MARKET CHANGE:

\title{
Upgrading of the non-residential building stock towards nZEB standard
}

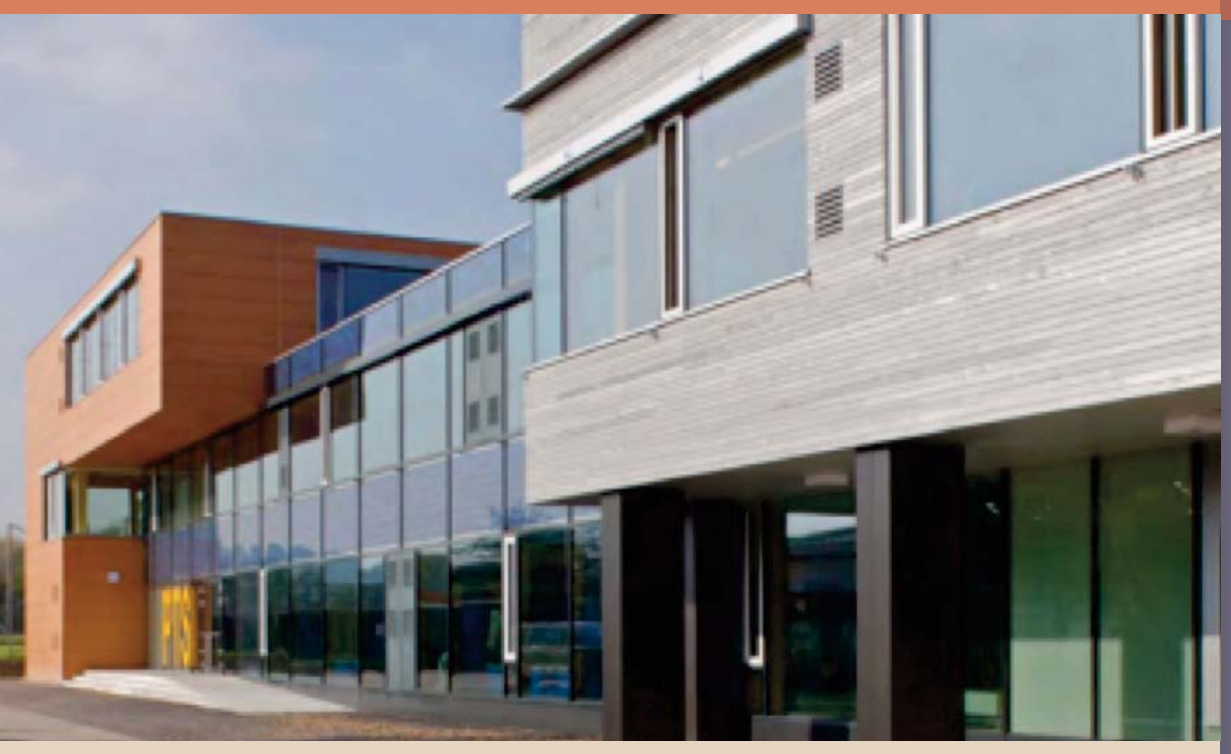

Recommendations to authorities and construction industry

Report number T.47.B.1 Date: 31.12 .14 

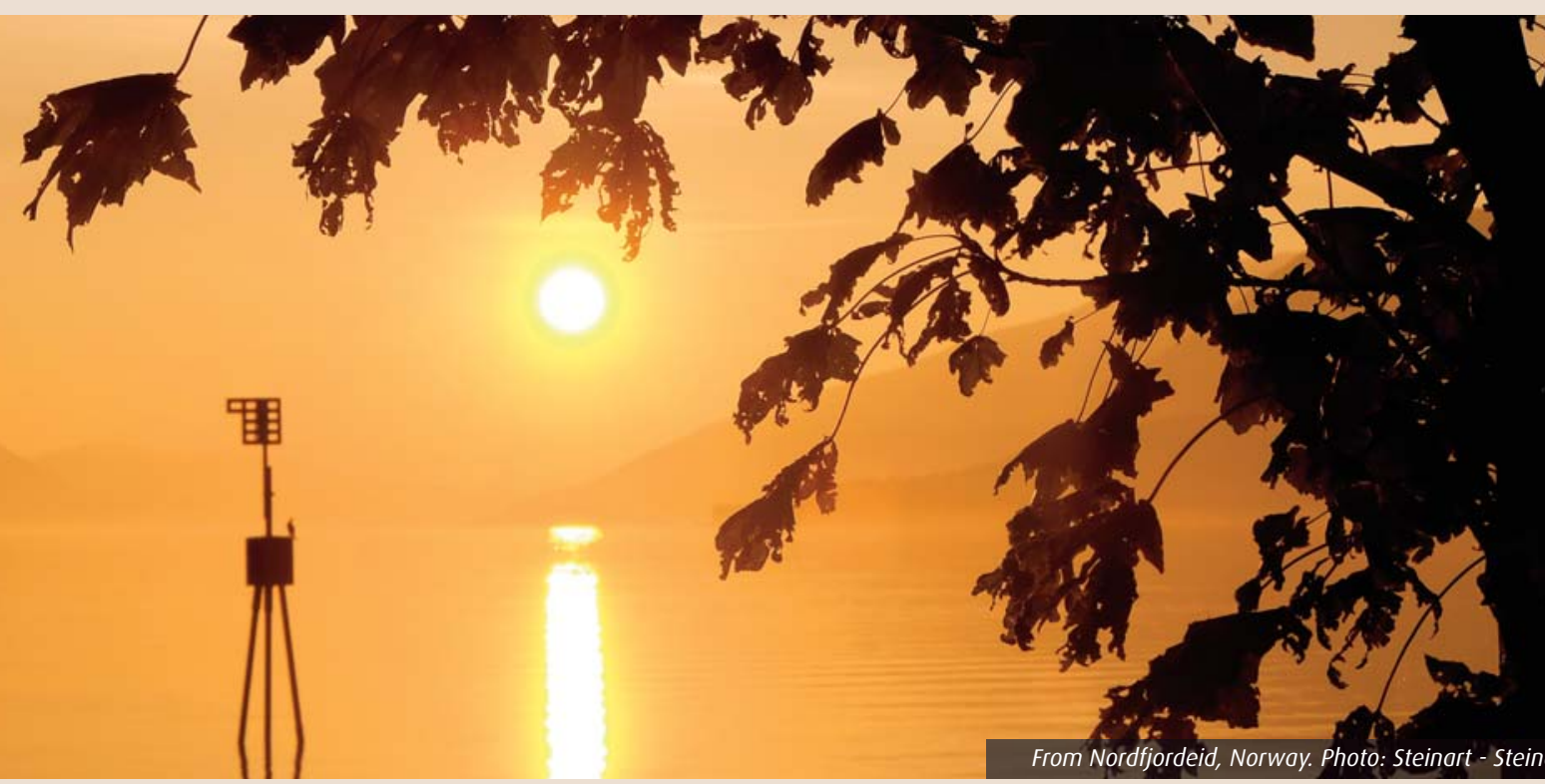

t.
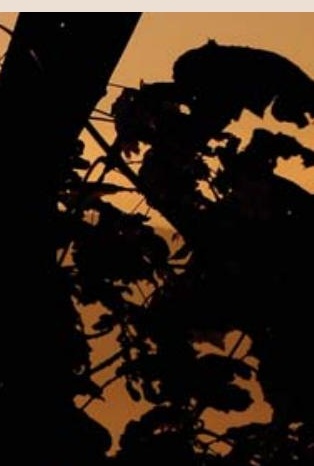

72
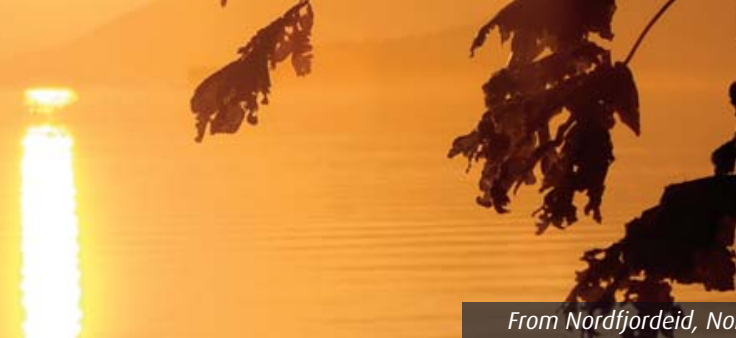

From Nordfjordeid, Norway. Photo: Steinart - Steinar Engeland

\section{Authors:}

Trond Haavik and Paul Jacob Helgesen, Segel AS, Norway

Anna Svensson, SINTEF Byggforsk, Norway

Nathan Groenhout and Diego Arroyo, The University of Sydney, Australia

Ezilda Costanzo, ENEA, Italian National Agency for New Technologies, Energy and

Sustainable Economic Development, Italy

Thomas Mach, Technische Universität Graz, Austria

Claudia Dankl, ÖGUT, Austria

Gerhard Lang, Graz Energy Agency, Austria

Jørgen Rose and Kirsten Engelund Thomsen, Danish Building Research Institute, Aalborg University Copenhagen, Denmark

Wouter Hilderson, Passiefhuis-Platform vzw, Belgium

Inputs to the Austrian case study «Franciscan Monastery» and to the modernization of protected buildings have been provided by the project «denkmalaktiv2». This project is supported by the Austrian Climate and Energy Fund within the program «NEUE ENERGIEN 2020».

\section{Disclaimer}

\section{NOTICE:}

The Solar and Cooling Programme, also known as the Programme to Develop and Test Solar Heating and Cooling Systems, functions within a framework created by the International Energy Agencu (IEA). Views, findings and publications of the Solar Heating and Cooling Programme do not necessarily represent the views or policies of the IEA Secretariat or of all its individual member countries.

\section{$\sum$ enova \\ segel \\ (2) SINTEF
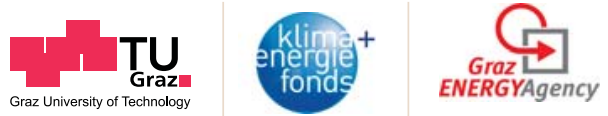 \\ $\overbrace{\text { bigut }}$ ENEA \\ passiefhuis-platform




\section{IEA Solar Heating and Cooling Programme}

The Solar Heating and Cooling Programme was founded in 1977 as one of the first multilateral technology initiatives («Implementing Agreements») of the International Energy Agency. Its mission is To enhance collective knowledge and application of solar heating and cooling through international collaboration.

The members of the Programme collaborate on projects (referred to as «Tasks») in the field of research, development, demonstration (RD\&D), and test methods for solar thermal energy and solar buildings.

A total of 53 such projects have been initiated to-date, 39 of which have been completed. Research topics include:

- Solar Space Heating and Water Heating (Tasks 14, 19, 26, 44)

- Solar Cooling (Tasks 25, 38, 48, 53)

- Solar Heat or Industrial or Agricultural Processes (Tasks 29, 33, 49)

- Solar District Heating (Tasks 7, 45)

- Solar Buildings/Architecture/Urban Planning (Tasks 8, 11, 12, 13, 20, 22, 23, 28, 37, 40, 41, 47, 51, 52)

- Solar Thermal \& PV (Tasks 16, 35)

- Daylighting/Lighting (Tasks 21, 31, 50)

- Materials/Components for Solar Heating and Cooling (Tasks 2, 3, 6, 10, 18, 27, 39)

- Standards, Certification, and Test Methods (Tasks 14, 24, 34, 43)

- Resource Assessment (Tasks 1, 4, 5, 9, 17, 36, 46)

- Storage of Solar Heat (Tasks 7, 32, 42)

In addition to the project work, there are a number of special activities:

- SHC International Conference on Solar Heating and Cooling for Buildings and Industry

- Solar Heat Worldwide - annual statistics publication

- Memorandum of Understanding with solar thermal trade organizations

\section{Members}
- Australia
- Austria
- Belgium
- China
- Canada
- Denmark
- ECREEE - Sponsor
- European Copper Institute - Sponsor
- European Commission
- Germany
- Gulf Organization for Research and Development - Sponsor
- Finland
- France
- Italy
- Mexico
- Netherlands
- Norway
- Portugal
- RCREEE - SpOnSOr
- Singapore
- South Africa
- Spain
- Sweden
- Switzerland
- Turkey
- United Kingdom
- United States

\section{Further information:}

For up to date information on the IEA SHC work, including many free publications, please visit www.iea-shc.org 


\section{CONTENTS}

$1 \quad$ Nomenclature and definitions 5

2 Introduction $\quad \mathbf{5}$

2.1 The challenge dealt with in IEA SHC Task 47

2.2 Objectives for Subtask B 6

2.3 Methodology and sub deliverables 6

3 Identifying the potential $\quad 7$

3.1 Building stock analyses in partner countries $\quad 7$

3.1.1 Australia 7

3.1.2 Denmark 9

$\begin{array}{lr}3.1 .3 \text { Norway } & 10\end{array}$

3.1.4 Italy

3.1.5 Europe 13

3.2 Discussion about the building stock analyses 15

4 Learning from decision making processes 16

4.1 Introduction and filtering 16

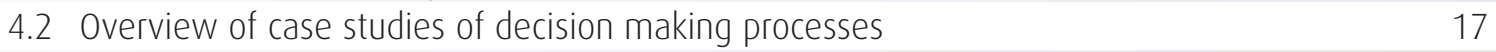

4.3 Characteristics of project stakeholders 20

4.4 Most important drivers for ambitious energy upgrading 21

4.5 Most important barriers for ambitious energy upgrading 24

4.6 Main lessons learned from studied decision making processes 27

$\begin{array}{ll}\text { 4.6.1 Summary of drivers and barriers } & 27\end{array}$

4.6.2 Clear understanding and definition of needs 32

$\begin{array}{ll}\text { 4.6.3 Value propositions which fulfill customer needs } & 34\end{array}$

4.6.4 Passionate and committed persons 35

4.6.5 Involvement of multi-disciplinary teams 36

$\begin{array}{ll}\text { 4.6.6 Organizational alignment } & 37\end{array}$

4.6.7 Summary of lessons learnt from decision making processes 39

5 Issues related to modernization of protected buildings 41

5.1 The conflict between preservation and change 41

5.2 Monument protection and climate protection 42

5.3 Results from the research project "denkmalaktiv I" 43

5.4 Need for action 47

6 Examples of existing decision making support tools 48

6.1 ECBS Annex $36 \quad 48$

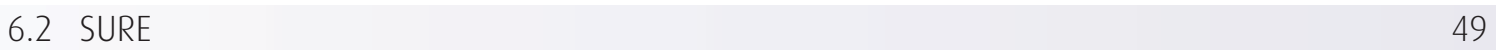

6.3 UPGRADE Solutions 49

6.4 Other examples 49

7 Recommendations $\quad 50$

$\begin{array}{ll}7.1 \text { Introduction } & 50\end{array}$

7.2 Recommendations to authorities 52

7.3 Recommendations to the construction industry 54

7.4 Final remark 56

References $\quad 57$

$\begin{array}{ll}\text { ANNEXES } & 59\end{array}$ 


\section{NOMENCLATURE AND DEFINITIONS}

International Energy Agency Solar Heating and Cooling Programme, Task 47 (IEA SHC Task 47) Net Zero Energy Buildings; a building where the net energy consumed over a year is matched by an equal amount of energy produced on site (nZEB)

European Union (EU)

The Directive on the energy performance of buildings (EPBD) is the Directive of the European Parliament and Council on energy efficiency of buildings

Non-energy benefits (NEB)

Million Tonnes of Oil Equivalent (Mtoe)

Giga Watt hours (GWh)

EU's Seventh Framework Program for Research and Technological Development (FP7)

Building Energy Management System (BEMS)

\section{INTRODUCTION}

\subsection{The challenge dealt with in IEA SHC Task 47}

Buildings are responsible for around $40 \%$ of the total primary energy consumption in most IEA participating countries [1].

Article 9 of the EPBD (2010/31/UE) Recast requires that:

(a) by 31st December 2020, all new buildings are nearly zero energy buildings; and

(b) after 31 December 2018, new buildings occupied and owned by public authorities are nearly zero energy buildings [2].

A few exemplary non-residential renovation projects have demonstrated that total primary energy consumption can be drastically reduced, together with improvements to indoor environment quality through renovation of a building's passive and active systems. Because most property owners are not even aware that such savings are possible, they tend to set less ambitious targets. Buildings that are renovated to mediocre performance can be a lost opportunity for decades.

The objectives of IEA SHC Task 47 are to develop a solid knowledge-base including: how to renovate non-residential buildings towards the Net Zero Energy Building standards NZEB in a sustainable and cost efficient way; ways to identify important market and policy issues; and effective marketing strategies for such renovations.

Task 47 is divided into four primary subtasks:

Subtask A: Advanced Exemplary Projects - Information Collection and Brief Analysis

Subtask B: Market and Policy Issues and Marketing Strategies

Subtask C: Assessment of Technical Solutions and Operational Management

Subtask D: Environmental and Health Impact Assessment

For more information about Task 47 please see: http://tosk47.ieo-shc.org/

This document summarizes the overall findings of the work undertaken in Subtask B - Market and Policy Issues and Marketing Strategies. 


\subsection{Objectives for Subtask B}

The specific objectives of Subtask B are:

- Identify building types with high potential for energy efficiency savings and the types of owners that are most likely to go for major renovation projects.

- Identify the most important barriers and drivers in decision making processes for high ambition renovation projects in the non residential sector and how to address them.

- Develop knowledge about which constraints are the most important and how to address them to make renovations attractive/affordable/cost effective and more available.

- Increase the understanding of how improved non-energy benefits, as a result of substantial renovation, increase the value of a building, and thereby makes the investment worthwhile.

The results of the subtask are relevant for these target groups:

- Local and national authorities

- Building owners (both public and private) which want to be frontrunners in net zero upgrading of existing buildings

- Construction industry (including architects) which want to be frontrunners in net zero upgrading of existing buildings

\subsection{Methodology and sub deliverables}

This report is a result of the following activities:

- Desktop studies of available building stock information and ownership structures in partner countries and résumés made by task experts from participating countries

- Interviews and in-depth descriptions of the decision making processes used in case studies from the participating countries, in order to identify barriers and driving forces. The interviews were carried out utilising a task specific questionnaire template (annex 5) which was developed by the subtask members at the start of the project.

- Two workshops within the Task to discuss preliminary findings

- A cross analysis of the above information, by the subtask leader, with contribution from the task experts, to identify trends, commonalities and differences across the participant countries and draw conclusions about the decision making process.

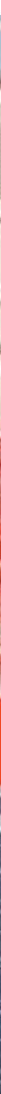




\section{IDENTIFYING THE POTENTIAL}

\subsection{Building stock analyses in partner countries}

A brief introduction to available non-residential building stock information for Australia, Denmark, Norway, Italy and for Europe in general is presented in the next sub chapters.

\subsubsection{Australia}

There is currently no consolidated source of building floor area, use and energy consumption for the Australian building stock. A 2012 report published by the Department of Climate Change and Energy Efficiency into «Baseline Energy Consumption and Greenhouse Emissions in Commercial Buildings in Australia» [3] attempted to consolidate data from a range of sources and create a statistical model of the building stock.

The report can be found at http://www.industry.gov.au/Energy/EnergyEfficiency/Non-residentialBuildings/Documents/CBBS-Part-1.pdf.

According the report the non-residential building stock excluding industrial space was approximately $214 \mathrm{M}$ $\mathrm{m}^{2}$ in 2012. The largest sector is retail accounting for around 31\% of the total stock, followed by offices (29\%) and then schools (19\%).

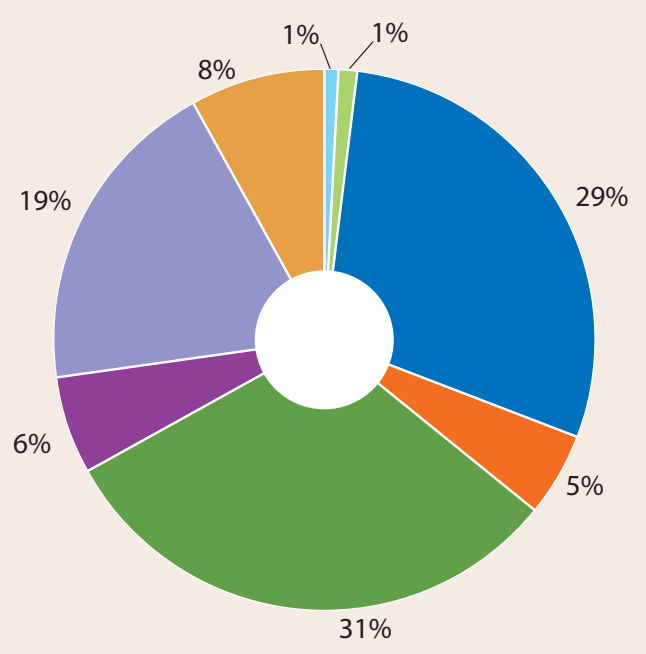

Office

Hotels

Retail

Hospital

Schools

University

Public Buildings

Law

Figure 1: Percentage area of Australian Non-Residential Building Stock

The energy consumption of these broad categories is difficult to ascertain in detail, with significant amounts of data not available, or from very small sample sizes. As such, retail was broken down further to consider only shopping centres and supermarkets but exclude strip retailing and office was broken down to include only standalone office space. On this basis the distribution of floor space is shown in the following figure. 

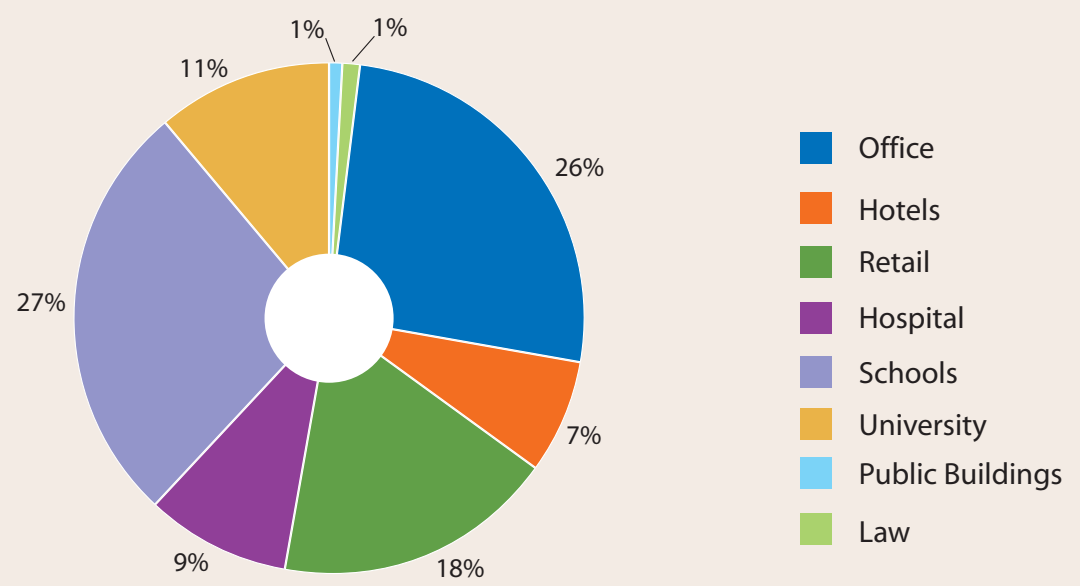

Figure 2: Percentage of adjusted area of Australian Non-Residential Building Stock

Based on known or estimated energy use data, schools (27\%), office (26\%) and retail (18\%) represent the largest floor areas of the total $151 \mathrm{M} \mathrm{m}^{2}$. When schools, vocational training and university buildings are combined they represent 38\% of the building stock.

As a percentage of energy use, based on the $151 \mathrm{M} \mathrm{m}^{2}$, the following figure highlights that Retail represents 35\% of the energy consumed, compared to 25\% for offices, and 14\% for hospital buildings.

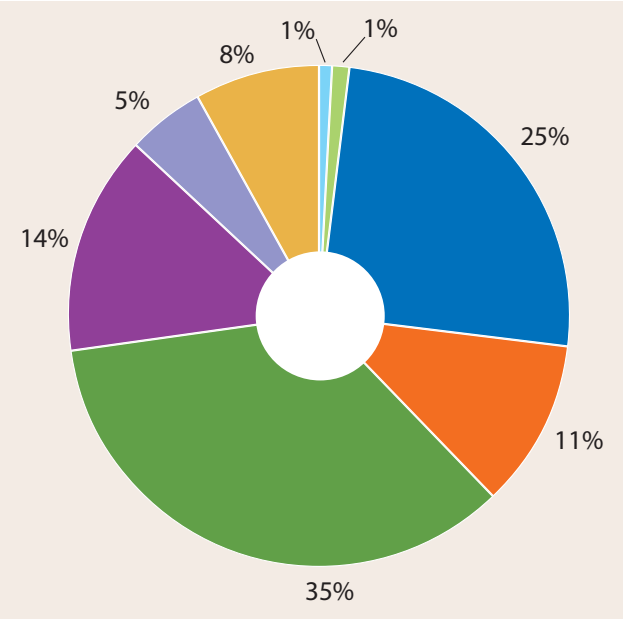

Office

Hotels

Retail

Hospital

Schools

University

Public Buildings

Law

Figure 3: Percentage energy use of Australian Non-Residential Building Stock

When energy consumption is normalised on a $\mathrm{kWh} / \mathrm{m}^{2}$ per annum basis, retail is the most energy intensive sector at $508 \mathrm{kWh} / \mathrm{m}^{2}$ per annum, compared to $248 \mathrm{kWh} / \mathrm{m}^{2}$ per annum for office space and just $91 \mathrm{kWh} / \mathrm{m}^{2}$ per annum for the education sector. The second and third largest energy intensive sectors are hospitals at $439 \mathrm{kWh} / \mathrm{m}^{2}$ per annum and hotels at $419 \mathrm{kWh} / \mathrm{m}^{2}$ per annum.

As a large energy consumer, commercial office space has attracted considerable focus over the past decade or more in Australia with a range of programs, rating schemes and technologies focused on improving energy efficiency and reducing energy demand in commercial offices. 
The data in the report highlights that retail spaces represent opportunities for energy savings and greenhouse gas reduction due to their large floor area and energy intensiveness.

Hospitals respresent a similar floor area to education but use more than four times as much energy. The operating profile of a hospital also makes it more difficult to apply standardised approaches to energy reduction compared to office buildings or even educational facilities.

In public sector buildings such as hospitals and education facilities, there is continual challenge of directing public funds into the delivery of services such as healthcare or teaching, rather than into capital investments to realise long term operational savings.

Therefore key challenges facing stakeholders seeking ambitious renovation projects in Australia include:

- Climatic influences: Australia has a broad range of climate zones from cool to tropical. Therefore a range of technological, passive and active solutions are required.

- Public sector agencies are limited by availability of funding for public sector demonstration projects, policy shifts in government priorities and programmes, and perceived value to taxpayers

- Private sector clients face challenges in access to debt and equity to finance upgrades, particularly in the face of split incentives, and over supply of highly incentivesed higher grade stock limiting returns for refurbishment of existing stock.

\subsubsection{Denmark}

The total Danish non-residential building stock excluded buildings without heating plant and listed buildings covers $101 \mathrm{M} \mathrm{m}^{2}$ BRA [4].

The distribution by building categories is shown in figure 4 :
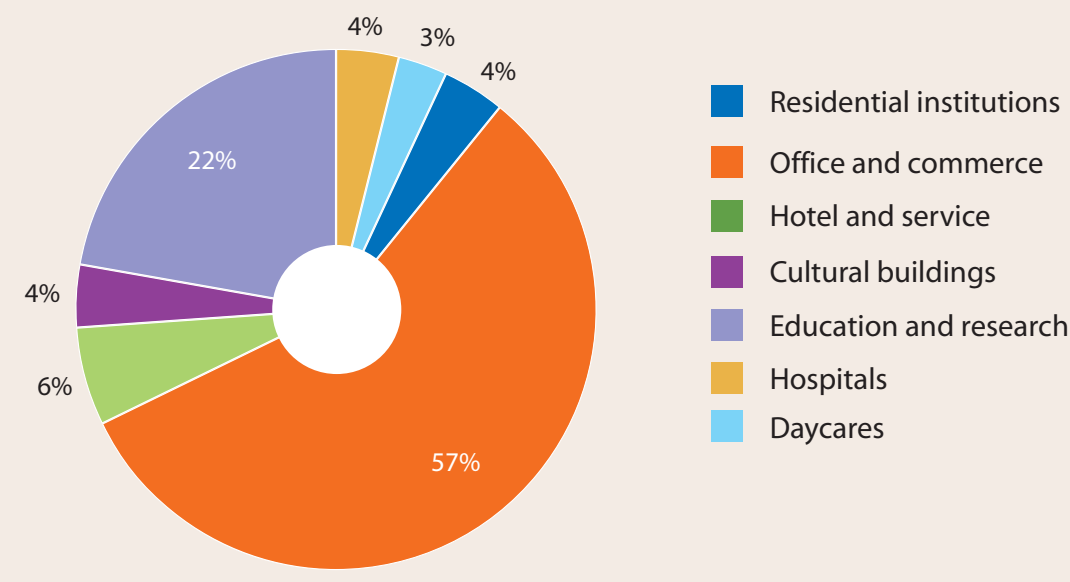

Hospitals

Daycares

Figure 4: Percentage area of Danish Non-Residential Building Stock

The wide category - Office and Commerce - account for the largest proportion of buildings with 57\% of the total non-residential building stock. Education and Research is the second biggest category with 22\%.

Only 4\% of office and commercial buildings are publicly owned, while public ownership accounts for 43\% of education and research buildings [5]. 
The potential for energy saving in the Danish building stock is estimated in the report «Varmebesparelse ved løbende bygningsrenovering frem til 2050» (heat savings by continously retrofitting towards 2050), by the Netværk for energirenovering, SBi [4].

In the study, several scenarios are studied, and it is shown that the «business as usual scenario» will result in yearly savings of 10,544 TJ by 2050, which corresponds to a saving of $21.8 \%$ of the total energy used in the non-residential building stock. This scenario is based on the assumption that additional insulation is added and building componets are replaced only when they are worn out, and then upgraded according to the most current building code at the time of renovation.

The greatest savings are found in offices and commercial, as well as educational and research buildings built before 1960. These buildings can save between 28\% and 34\% of the total energy demand, depending upon the year of construction. More information about the Danish study can be found in annex 1.

\subsubsection{Norway}

The Norwegian non-residential building stock is broken down into the following ownership structure (as percentage of total $\mathrm{m}^{2} \mathrm{BRA}$ ):

$\begin{array}{lr}\text { Private sector } & 61 \% \\ \text { State bodies } & 10 \% \\ \text { Regional authorities } & 8 \% \\ \text { Municipalities } & 21 \%\end{array}$

The total available floor space within the Norwegian non-residential building stock is $125 \mathrm{M} \mathrm{m}^{2}$ BRA. Commercial/retail buildings, other Industry and Offices account for the majority of the space (almost 70\%) as illustrated below in figure 5 [6]:

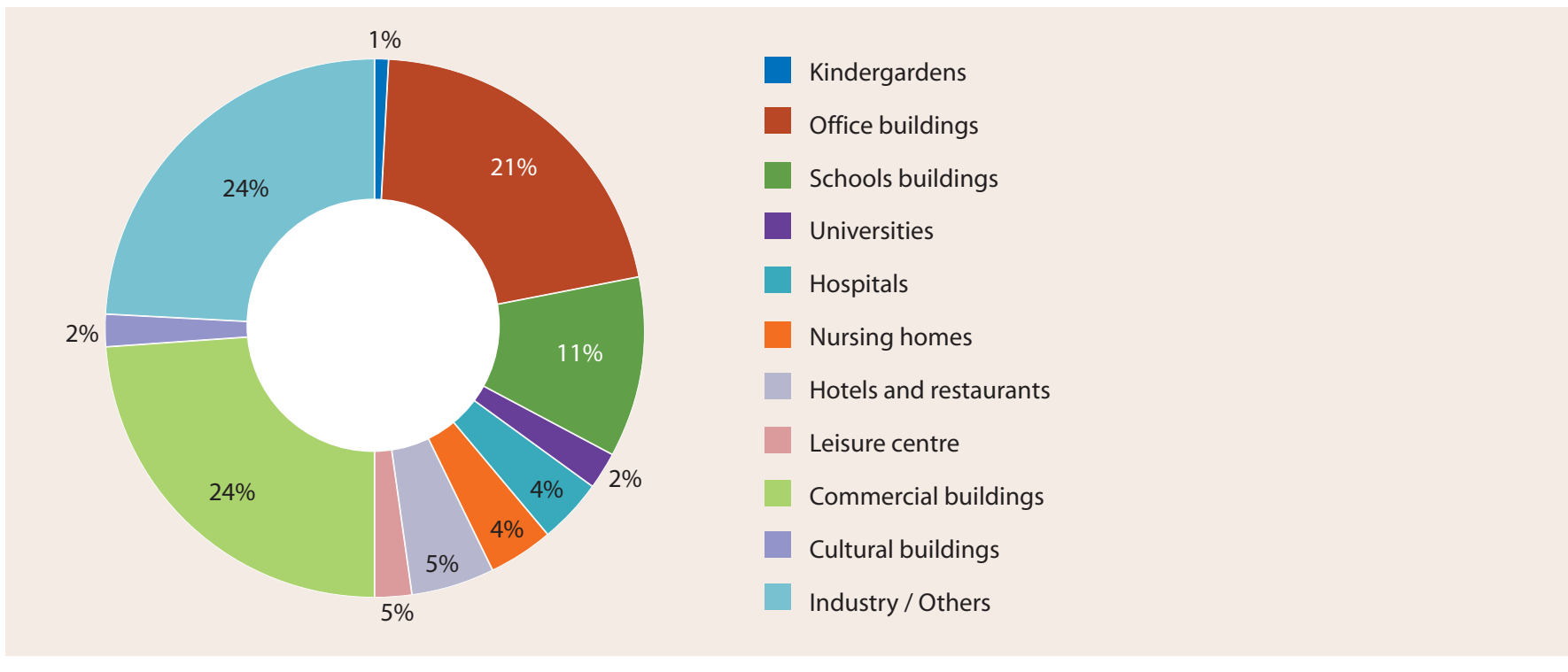

Figure 5. Percentage area of Norwegian Non-Residential Building Stock

Figure 6 shows that commercial/retail buildings have the highest energy use of all categories. Offices account for the second highest energy consumption. 

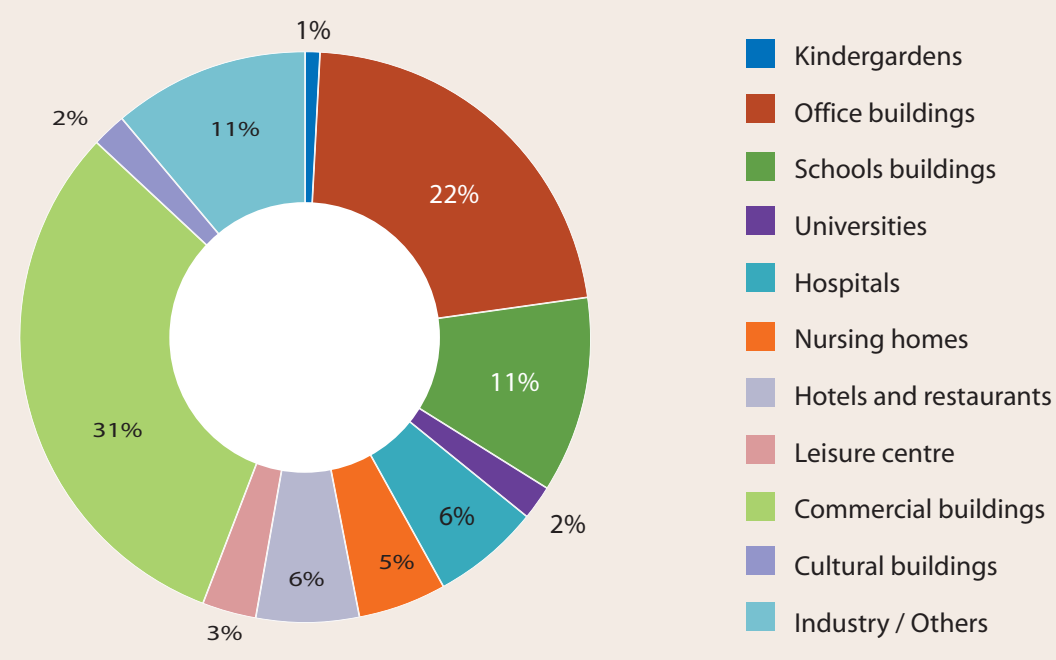

Figure 6 Percentage energy use of Norwegian Non-Residential Building Stock

Figure 7 illustrates the available building space distributed by construction year and by building category.

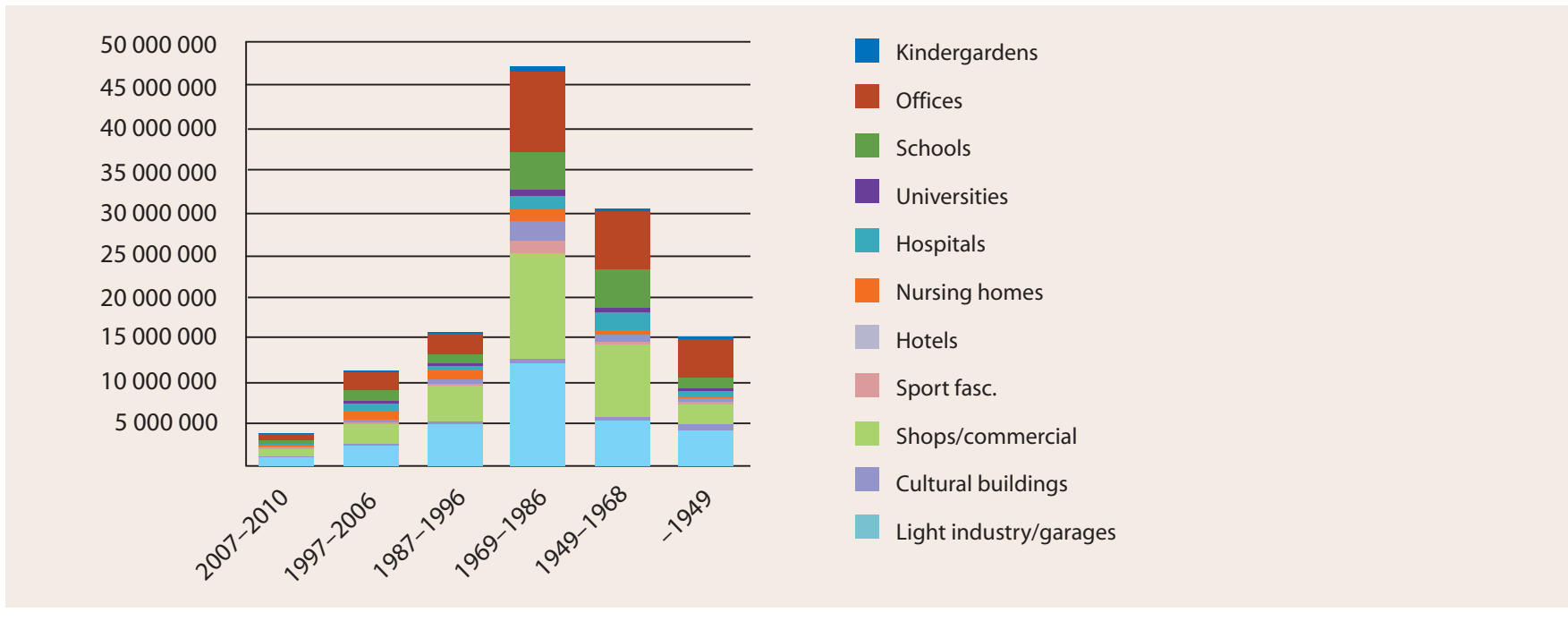

Figure 7 Use of area by building year and building category in Norway.

From this data, it can be seen that the greatest potential lies in shops/commercial buildings followed by office buildings, industry and school buildings, based on total area available.

Taking into account the ownership structure it means that the following stakeholders are the most influential to motivate increasing ambitions when upgrading buildings:

1. Private owners of retail buildings

2. Private owners light industry/garage buildings

3. Private owners of office buildings

4. Municipalities

Regarding the third group, both state and regional authorities are also owners of office buildings which may serve as good examples for private owners.

For more information about the Norwegian building stock please see annex 2. 


\subsubsection{Italy}

In Italy there are nearly 1,770,000 non-residential buildings and about 400,000 host recreational and sports activities, schools, hospitals and churches.

The available statistics for Italy are not complete, but for these categories the number, surface and volume are specified [7] :

\begin{tabular}{|l|l|l|l|}
\hline Schools & Number & $\begin{array}{l}\text { Surface Area } \\
\text { Million } \mathrm{m}^{2}\end{array}$ & $\begin{array}{l}\text { Volume } \\
\text { Million } \mathrm{m}^{3}\end{array}$ \\
\hline - Of which public schools & 51,904 & 73.2 & 256.4 \\
\hline Office buildings & 42,000 & & \\
\hline - Of which public owned or occupied & 64,911 & 56.7 & 200 \\
\hline Shopping centres & 13,581 & & \\
\hline Hotels & 1,114 & 16 (gross area) & \\
\hline Bank buildings & 25,845 & 48.6 & 140 \\
\hline
\end{tabular}

Table 1: Number of buildings, area and volume for selected Italian non-residential buildings

Important categories not included in the table above are; military buildings, all types of industrial building, nursery homes, etc.

Energy features of the Italion non-residential stock include:

- Non-residential buildings are responsible for around one third of the energy consumption of the entire building sector

- Consumption is continuously increasing and rose from 9,5 Mtoe or $110.5 \mathrm{GWh} /$ year (2005) to 18,9 Mtoe or $219.8 \mathrm{GWh} /$ year (2011)

- Electricity consumption in 2013 has doubled compared to 1990, mainly due to space cooling and appliance use

- Main energy sources are almost exclusively gas (50.4\%) and electricity (45.4\%).

- Understanding energy use is complex, as end-uses such as lighting, ventilation, heating, cooling, refrigeration, IT equipment and appliances vary greatly from one building category to another

- Building typologies are quite different in the different geographic and climatic zones

- Obsolete existing buildings consume 70\% - 80\% more than new buildings.

Nearly $60 \%$ of the Italian non-residential building stock has a need for retrofitting including functional upgrading and improved energy efficiency.

In order to estimate savings by 2020, an analysis has been made of buildings such as offices, schools, hotels, banks and shopping centers whose energy consumption is 50\% higher than the benchmark.

The floor areas of the public and private buildings which each year can be renovated effectively, i.e. renovated with a mix of combinations that take into account the climate characteristics at the building's location, have been estimated to be: 5.5 million $\mathrm{m} 2$ for office use (about 2000 buildings), 6.0 Million m2 for school use (about 3800 buildings), 1.5 million m2 for hotels (about 500 buildings).

This will lead to the following energy sovings rates:

- $60 \%$ in the public sector

- $45 \%$ in the private sector

- 35\% for shopping centers only 
The estimated investments for these projects amount to EUR 17.5 billion per annum, and should yield potential energy savings by 2020 of some 17,229 GWh/year, equivalent to 1.49 Mtoe/year.

A closer study of the potential for energy savings in school and office buildings has been carried out by ENEA and shows the number of buildings distributed by construction year:
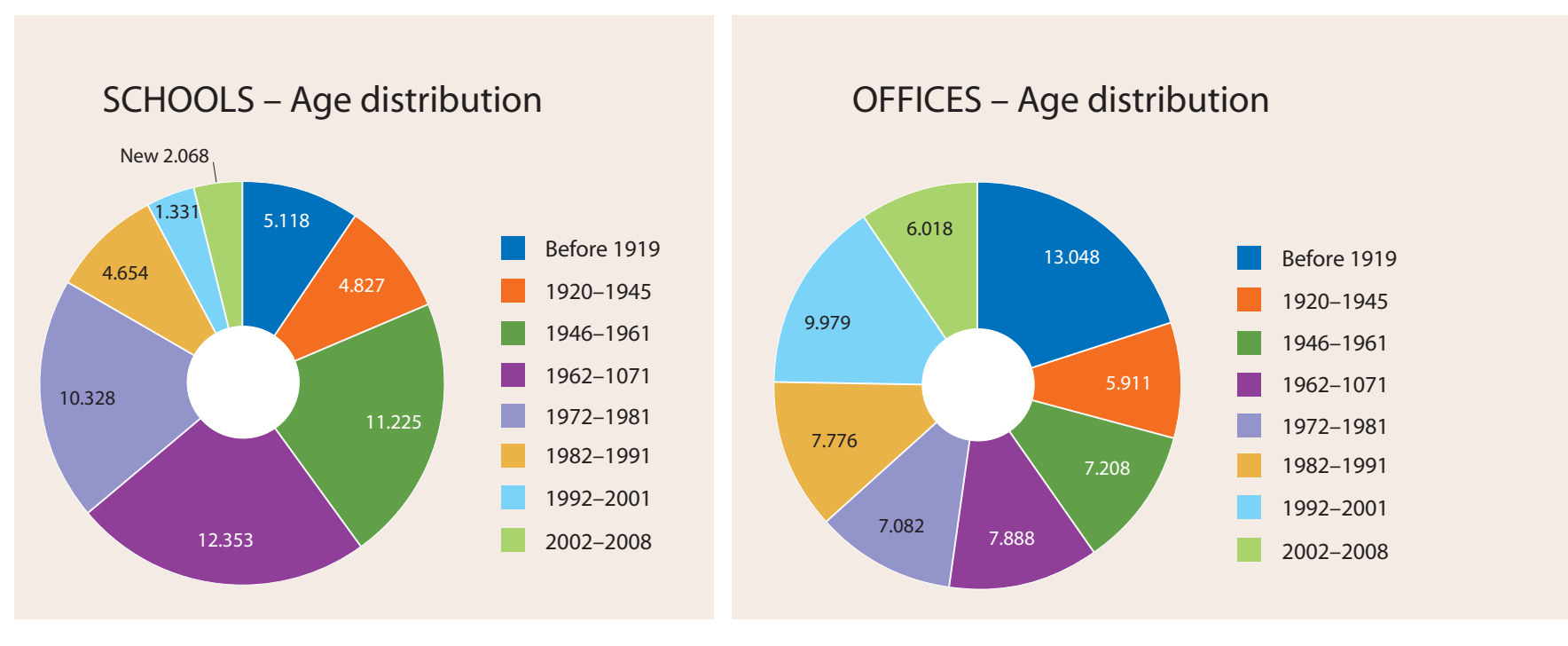

Figure 8- Age distribution of school and office buildings in Italy

Potential annual savings for public schools and offices are shown in table 2:

\section{SCHOOLS (Annual savings at 2020)}

0.39 Mtoe $(4,53 \mathrm{GWh} /$ year $)$

$33,36 \%$ public schools consumptions

\section{OFFICES}

0.16 Mtoe (1,86 GWh/year)

23,27\% public offices consumptions

Table 2 - Savings estimated by renovating public schools and office buildings

For more information about the Italian building stock and the assumptions for calculating the potential for energy savings in Italian non-residential buildings see annex 3.

\subsubsection{Europe}

BPIE's «Europe's Buildings under the Microscope» [8] analyzed the building stock in the 27 EU member states plus Norway and Switzerland. Non-residential buildings cover 25\% of the total floor area of the European building stock.

Figure 9 shows the distribution of floor area $\left(\mathrm{m}^{2}\right)$ per category of non-residential buildings in Europe presented in the BPIE report. 


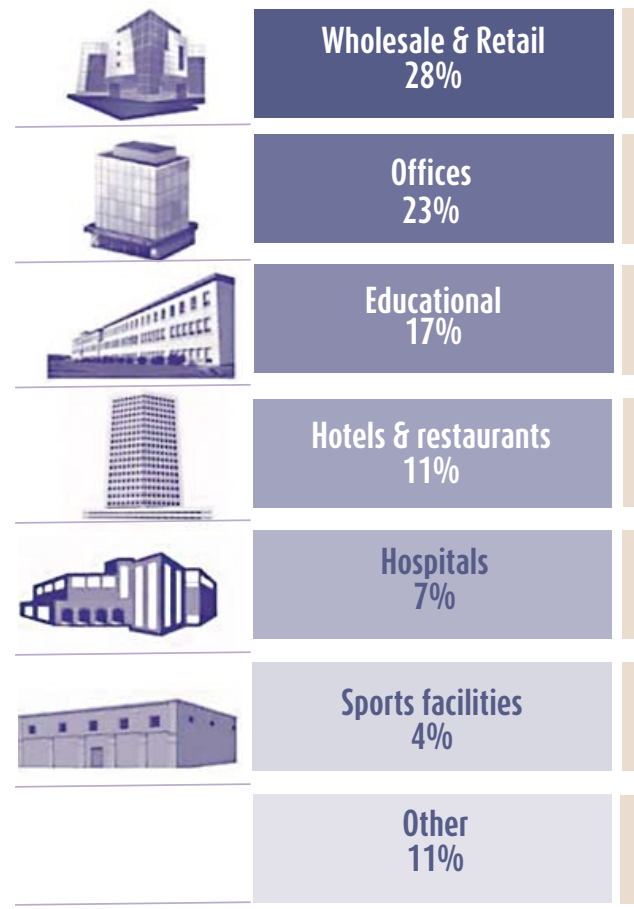

Detached shops. shopping centres, department stores, large and small retail, food and non food shops, bakeries, car sales and maintenance, hair dresser, laundry, service stations (in gas stations), fair and congress buildings and other wholesale and retail.

Offices in private companies and offices in all state, municipal and other adminsitrative buildings, postoffices.

Primary and secondary schools, high schools and universities, research laboratories, professional training activities and others.

Figure 9: Percentage of floor area $\left(\mathrm{m}^{2}\right)$ per category of non-residential buildings in Europe

The study shows that the highest energy use is within:

1. Shops $(28 \%)$

2. Offices (26\%)

3. Educational (12\%)

4. Hotels and restaurants (12\%)

These are followed by hospitals (10\%), sport facilities (6\%) and the remaining 6\% is by other types of energy consuming buildings.

In the report it is stoted:

"The average specific energy consumption in the non-residential sector is $280 \mathrm{kWh} / \mathrm{m}^{2}$ (covering all end-uses) which is at least 40\% greater than the equivalent value for the residential sector. In the nonresidential sector, electricity use over the last 20 years has increased by a remarkable 74\%.»

\section{Ownership}

There are no complete statistics for all countries regarding ownership. For the fifteen countries with available data, the ownership of non-residential buildings vary considerably. The countries with the highest share of private ownership are Greece (approx 89\%), Latvia (approx 88\%), Denmark and Lithuania (both approx 81\%). Those with the lowest share of private ownership are Estonia (approx 9\%), Bulgary (approx 13\%) and Hungary (approx 28\%).

Link to the full report:

http://www.bpie.eu/uploads/lib/document/attachment/20/HR_EU_B_under_microscope_study.pdf 


\subsection{Discussion about the building stock analyses}

The three largest building categories, based on floor area $\left(\mathrm{m}^{2}\right)$ are commercial/retail buildings, offices and educational buildings. The relative energy use of these segments varies to the relative distribution of floor space; for example in Norway the most significant difference is in commercial/retail buildings which have a higher share of the total energy use (31\% of all energy use) compared to the total floor space (24\% of total floor space). Future research projects should therefore focus on the opportunities for high ambition retrofitting projects within this segment. The focus in IEA SHC Task 47 has primarily focussed offices and school buildings.

The majority of office buildings throughout the countries studied are typically privately owned with state and regional public bodies the next largest owner group. This means that in order to move this market it is necessary to motivate private owners. Typically, private owners seek to maximize return on their investment and hence investment of capital in upgrading existing buildings must show strong returns on capital. A common issue facing this sector is the concept of a split incentive. The owner must invest the capital to renovate the building, but the tenant gains the benefit through reduced running costs and improved internal environments. Unless the owner can recoup the investment through higher rent, the tenant gets all the benefit. To overcome this market resistance, governments must consider regulatory intervention through increasingly tighter building standards and regulations or offer incentives, rebates, tax breaks and grants to encourage owners to make the investment in renovation.

Throughout the study of participants, the largest proportion of schools are publicly owned and operated. A key question is therefore how to encourage public bodies to upgrade poor performing existing buildings (typically built before the 1980s, with poor energy efficiency and often poor indoor comfort) to current standards. This is one of the key questions the research within Subtask B will discuss in this report through learnings from the case studies discussed in the following chapters.

Based on the known building stock analysis it seems that any future research project should focus on:

- Retail buildings, with the main focus directed towards shopping centers owned by major retail chains.

- Educational buildings due to their high energy saving potential.

- Hospitals and aged care facilities (due to the increasing need for community housing and higher care facilities as a consequence of an aging population in most of the participant countries) also represent a huge potential due to the energy intensity of their operations and often continuous operating profile.

- Across the different building types, the experts see a large potential in historic buildings. These buildings also face more complicated decision-making processes (see chapter 5).

In an internal workshop in IEA SHC Task 47, it was demonstrated that the experts have mixed experiences regarding attitudes among private and public stakeholders with regard to renovation. Public clients are often easier to work with and will generally be willing to undertake demonstration or exemplar projects to encourage innovation and technology diffusion, but at the same time tendering processes often complicate innovative projects in the construction sector through purchasing rules and probity considerations. In the private sector, lowest cost and regulatory compliance are often the primary consideration, thereby reducing innovation and technological advancement. Statements might often include: «its too expensive», «it is untried technology», «its too risky». These comments are often unfounded and can be adequately dealth with by the design team during the project development phases. 


\section{LEARNING FROM DECISION MAKING PROCESSES}

\subsection{Introduction and filtering}

The purpose of studying decision making processes in NZEB retrofitting projects is to learn about the drivers and barriers that project stakeholders face in increasing the energy saving goals for renovation projects.

As NZEB retrofitting of non-residential buildings is still at an early market stage as defined in Roger's product development curve [9], each project may be recognized as an innovation project.

Carlson and Wilmot [10] defined five major factors which all have to be in place in order to succeed in launching a new product or service:

1) There must be a clear need as a customer value

2) A clear value proposition (needs+approach+benefits+competition)

3) People who are passionate and committed

4) Innovation teams, i.e. collective intelligence

5) Organizational alignment, i.e. supported by top management and company strategies

In the context of this work, the subtask activities considered how the case studies hove dealt with these issues, including:

- Is there a holistic understanding of the tenant's and owner's needs - which normally encompass more than just energy efficiency?

- Is the suggested solution offering value which fulfils those needs completely?

- Are there one or more enthusiastic persons who are committed to the process?

- Is there a multi-disciplinary team (also involving the owner/tenant)?

- How is the project supported by top management and is it in line with the company strategy?

In the second level of filtering of the information from the different projects we look at what are the identified drivers and barriers through the steps of the upgrading process. As figure 10 illustrates, every upgrading process starts with the project initiation, which is normally due to a variety of reasons including diminishing asset returns, asset protection, building obselesence, market competition or changes to government regulations. This is followed by defining what is needed to be done in the specific project. Either through a formal open tendering process (typically used for public sector projects) or by an invitation, or select tender, to a limited number of engineering/architectural firms (typically used for private sector projects) the planning and design team is recruited. Then the planning and design of preferred solutions for upgrading of the envelope along with the plant and services for the building are decided. The end result of these steps is the production of suitable documentation to be used in the tender for the construction work. After completing the construction work, the building is handed over to the owner. At the end the project is evaluated. 
BARRIERS

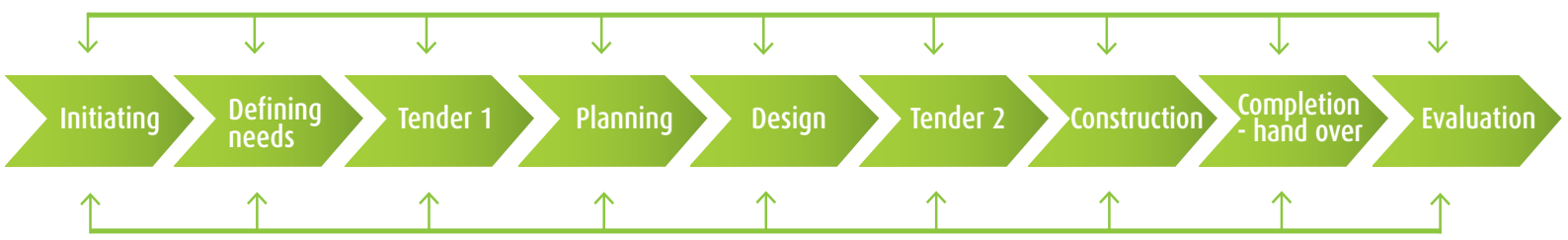

Figure 10: Typical upgrading process

\section{DRIVERS}

The following sections provide short introductions to each of the ten case studies investigated. After a description of the key project participants, the identified drivers and barriers for each of the case stories are presented. In the final section a summary of drivers and barriers are discussed as they relate to the process in figure 10. Finally we discuss how Carlson and Wilmot's five fundaments have been dealt with in these high ambition upgrading projects.

\subsection{Overview of case studies of decision making processes}

\begin{tabular}{|c|c|}
\hline \multicolumn{2}{|l|}{ OFFICE BUILDINGS } \\
\hline $\begin{array}{l}\text { IAG House, } \\
388 \text { George Street, } \\
\text { Sydney, Australia }\end{array}$ & 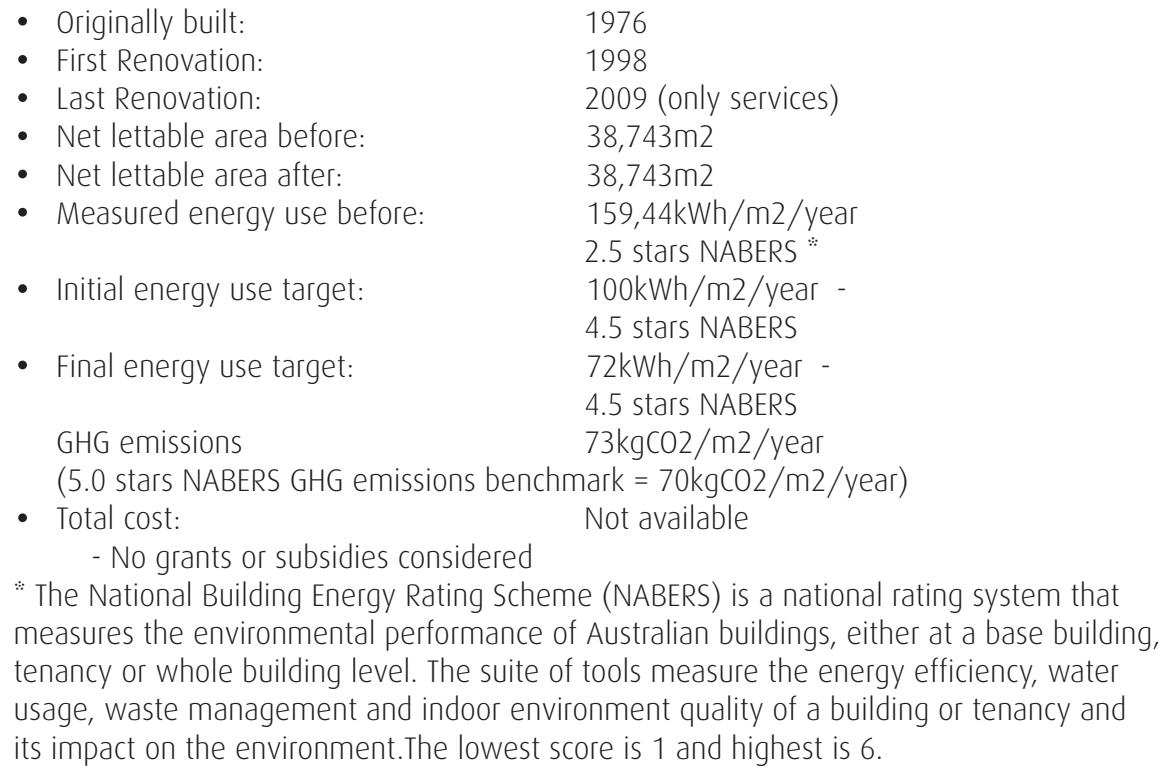 \\
\hline $\begin{array}{l}\text { Science Montoyer, } \\
\text { Brussels, Belgium }\end{array}$ & $\begin{array}{lll}\text { - } & \text { Originally built } & 1958 \\
\text { - } & \text { Net lettable area: } & 6,879 \mathrm{~m}^{2} \\
\text { - } & \text { Planned net energy consumption.: } & 20 \mathrm{kWh} / \mathrm{m} 2 / \text { year } \\
\text { - } & \text { Total cost: } & € 8.5 \mathrm{M} \\
& \text { - Estimated to be } 8 \% \text { higher than if built according to building code } \\
\text { - } & \text { Financial grant through BatEx: } & 200.000 €\end{array}$ \\
\hline
\end{tabular}




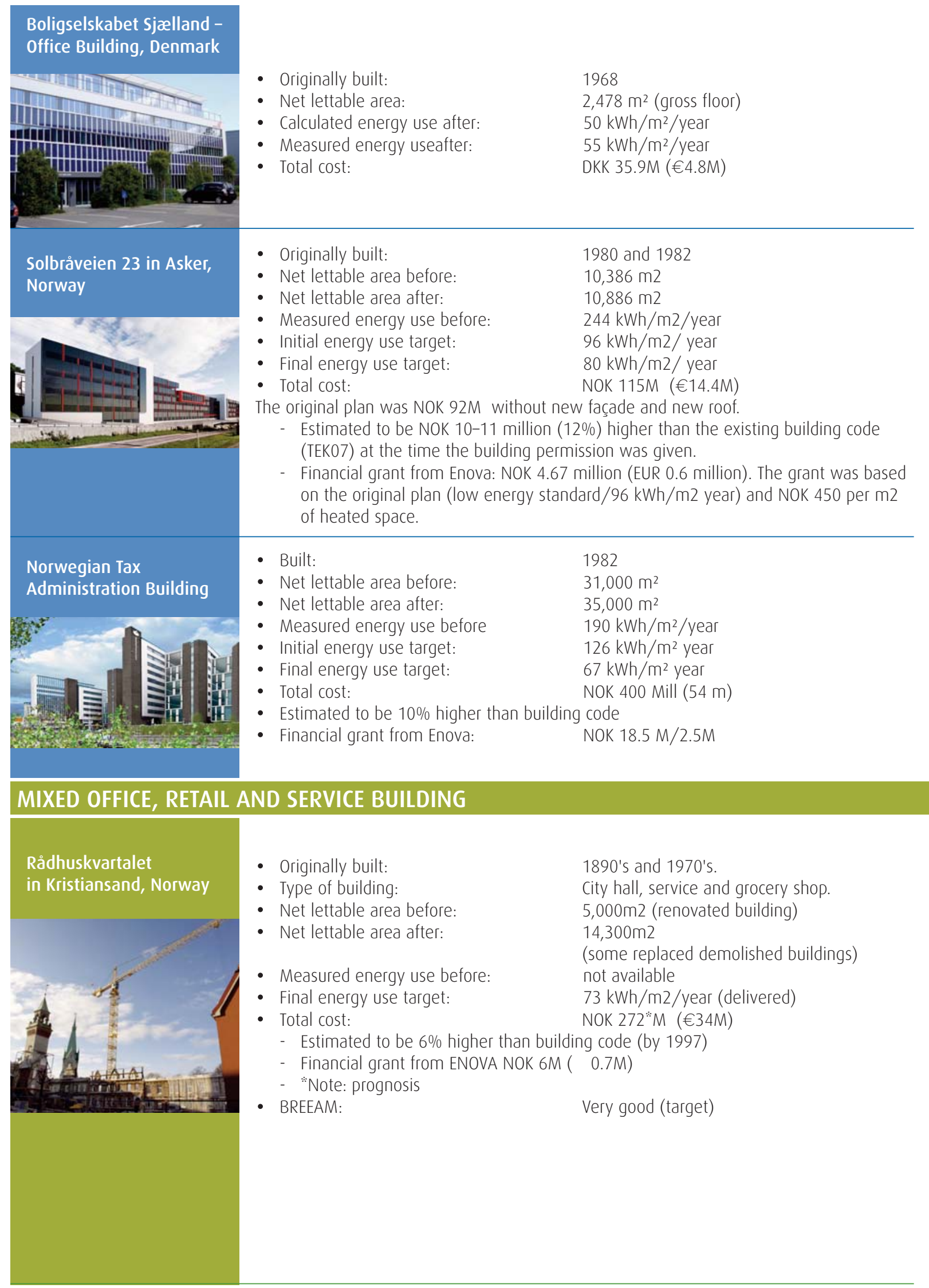




\section{SCHOOLS/KINDERGARTEN}

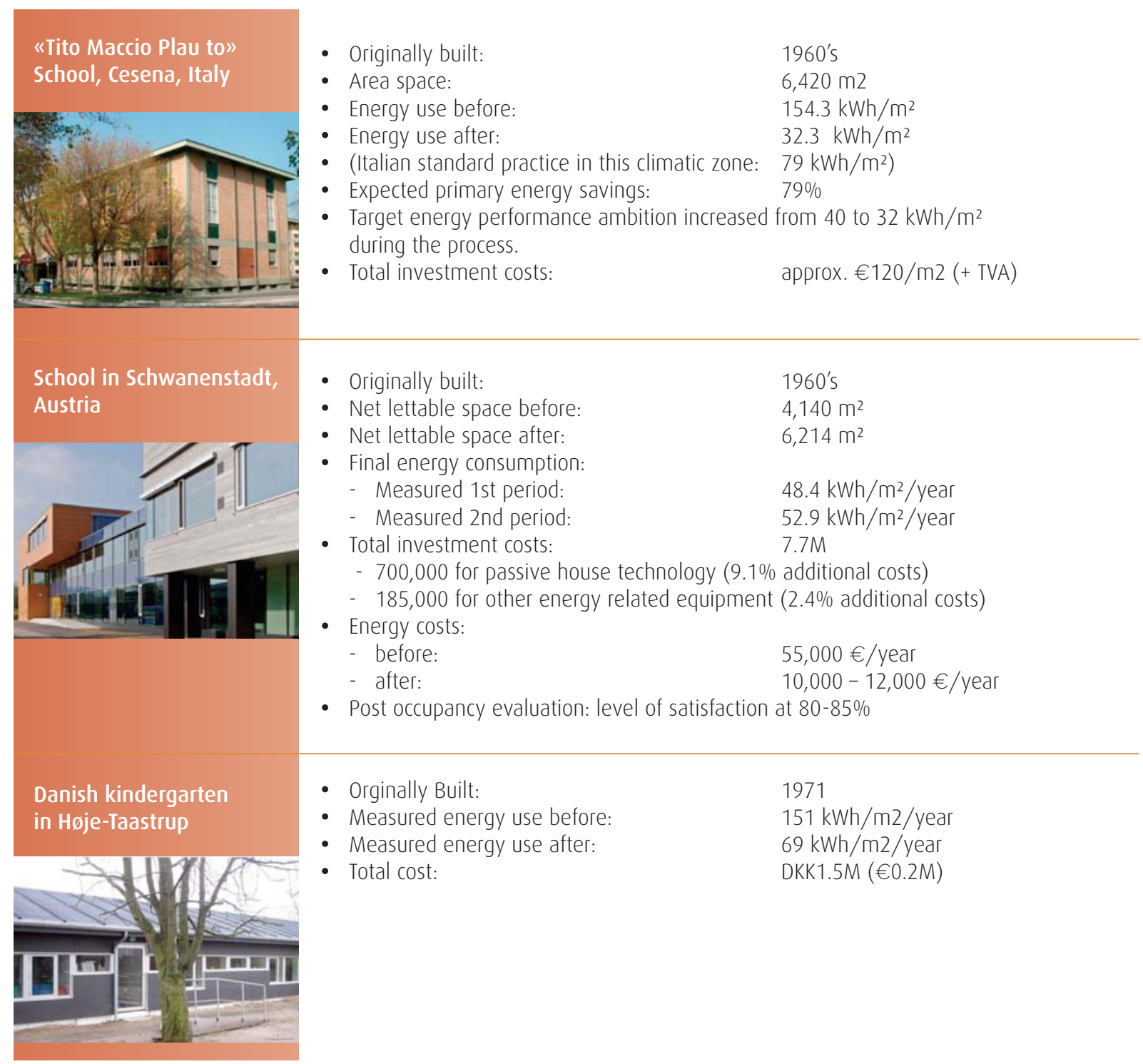

\section{MONASTERY}

Franciscan monastery, Graz, Austria

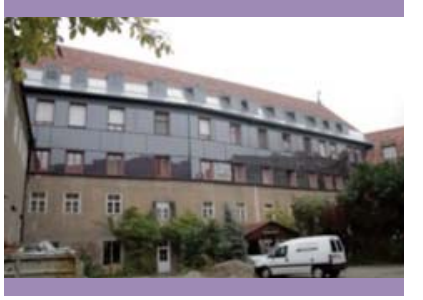

Table 3: Overview of case stories
- Built: between 1239 and 1648 (including enlargements and rebuildings)

- Currently fifteen monks live in the monastery

- Type of building: Franciscan monastery, medieval building structure, part of the historic city walls of Graz, part of the protected historic inner city

- Net lettable floor area before: $\quad 3,590 \mathrm{~m}^{2}$

- Net floor area after: $\quad 3,585 \mathrm{~m}^{2}$

- Energy use before: $198 \mathrm{kWh} / \mathrm{m}^{2} /$ year

- Energy use to be expected after the renovation: $85 \mathrm{kWh} / \mathrm{m}^{2} /$ year

- Expected total costs of renovation: $\quad € 4.2 \mathrm{M}$ by project close-out 


\subsection{Characteristics of project stakeholders}

The case studies investigated involve both private and public building owners. A common theme for all projects has been the presence of one or more innovation-oriented people within the client organization, or among the companies involved on the supply side. These individuals tend to drive innovative and creative thinking in others who are more traditional in their thinking, and even some who are sceptical about going beyond the existing building code.

This also demonstrates the point of Rogers' curve [9] for diffusion of innovation - that the development of a new market has to start with the innovators before the early adopters take on the idea in the growth phase:

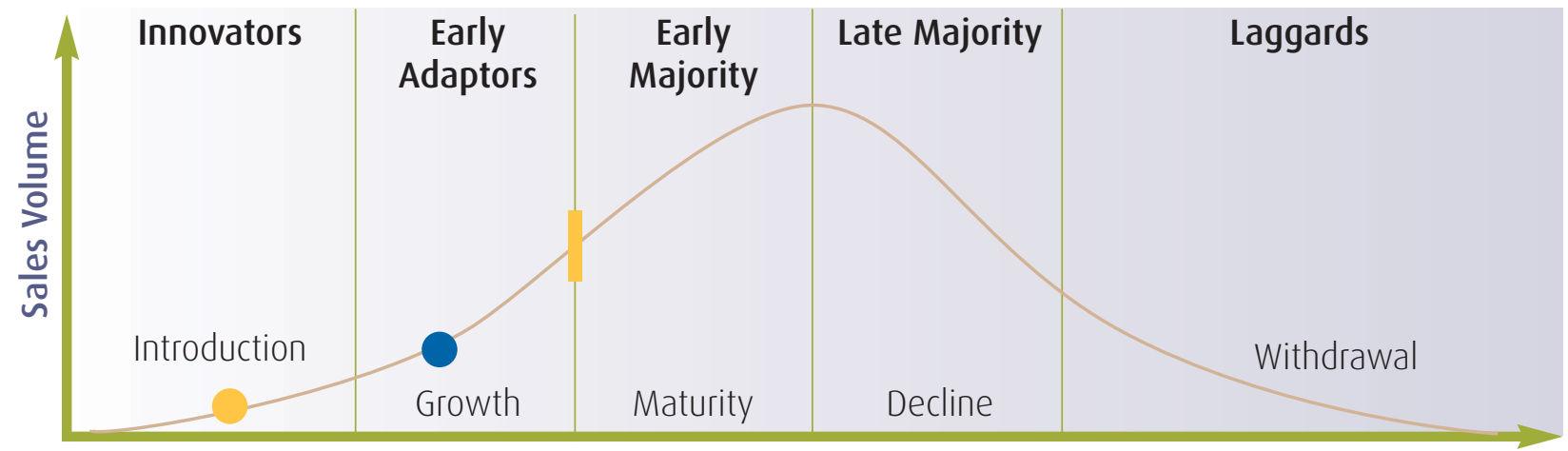

Figure 11: Curve for diffusion of innovation

Time

For successful high ambition renovation projects the first challenge for the Innovators (like we have seen with the case study projects) is to engage the Early Adopters. Once they are on board with the project, the next big challenge is to cross the chasm to get acceptance from the Early Majority.

Across the case studies we have examined how the main project participants relate to achieve high environmental ambitions. Here we have divided these participants into three characteristic groups: building owners, planners / designers, and contractors / builders. In all the cases studied the building owners had high energy efficiency goals. Although energy efficiency was not rated as high importance for Solbråveien at the beginning of the project, it became a promoter for high ambitions as the project proceeded.

Among the constructors it is typical to find both contractors experienced in delivering high ambition projects, and others who use the project as an opportunity to learn and are enthusiastic about it. But it is also among this group that we find participants that could be considered more «neutral» regarding targeting high ambitions in environmental performance and energy savings. They are generally in the project to perform a particular assigned function and are uncomfortable challenging the status quo or "how we always do things». This reflects some of the barriers met by building owners in projects. "Poor access to knowledge». We will get back to that in chapter 4.6. 


\title{
4.4 Most important drivers for ambitious energy upgrading
}

\author{
PROJECT \\ IMPORTANT DRIVERS
}

\section{OFFICE BUILDINGS}

$\begin{array}{ll}\text { IAG House, } & \text { Request by tenant considered very important by building owner } \\ 388 \text { George Street, } & \text { Owner had strong sense of responsibility for their practices with respect to } \\ \text { Sydney, Australia } & \text { climate change } \\ \text { - } & \text { Desire to reduce high energy costs } \\ \text { - } & \text { Needed to meet the organization's policies with respect to corporate social } \\ & \text { responsibility } \\ \text { - } & \text { Improvement to indoor comfort for building occupants }\end{array}$

Science Montoyer,

Brussels, Belgium
- Clear strategy and goals from the start within the company

- Emphasis on long term client retention and good quality of the buildings

- The will to learn and to be a frontrunner

- The impact on the image of the owner

- The support from the facilitators

- The experience of the architect in renovating office buildings

- The holistic and open approach of BREEAM

- The project had a strong focus on energy efficiency to start with

- Desire to strengthen the company's green profile

- Increase office space within the building

- Improve the façade

- Improve the indoor climate

- Economic analysis of the cost and benefit of energy savings/investments

- Obtaining buy in for the project from the representative board.
Solbråveien 23

in Asker, Norway
- The owner wanted to attract long term tenants

- An unattractive façade which had to compete with new buildings

- Poor indoor comfort (including noise)

- A key stakeholder (Mr Espen Aronsen in GK Norge) strongly advocated for energy efficient solutions

- MB (contractor) has a green philosophy as part of their business concept; they looked systematically for improvements that were measurable

- The building was empty, which provided an opportunity to undertake a complete renovation

- Informal and open decision making processes built on trust between the main actors.

- There was already a focus on energy efficiency from the tenant's side

Norwegian Tax Administration Building
- Entra's new strategy to become the industry leader in environmental efficiency

- The energy consultant advocated strongly that it was feasible and sustainable to renovate to Passive House standard

- The project leader hired by the Norwegian Tax Administration (NTA) believed in the idea and convinced the landlord that the proposed solution would be good

- One of the key individuals at NTA was very enthusiastic about the idea and was an internal promoter of increased ambitions

- Enova's grant was the final argument (but not decisive) for concluding the proposed alternative. Enova's support encouraged the decision makers to see this as a prestigious and sustainable visionary project

- The top management in both NTA and Entra saw that the project would support their respective organizations' social responsibility and thereby strengthen their public image 


\section{MIXED OFFICE, RETAIL AND SERVICE BUILDING}

Rådhuskvartalet in

Kristiansand, Norway
- Very enthusiastic and committed mayor with broad support

- Poor indoor quality within the existing building

- Need to co-locate the organization

- Highly respected internal project management which was committed to the idea of high ambitions

- Green policy and membership in Cities of the Future and Green Buildings

- Prestige of receiving grant from Enova

- The project itself became prestigious and resulted in strong commitment from the whole project team.

\section{SCHOOLS/KINDERGARTEN}

«Tito Maccio Plau

to» School,

Cesena, Italy

School in Schwanenstadt, Austria
- As a demonstration project each phase was regularly monitored. This was an important driver for increasing the renovation target ambition and timely delivery.

- Participation in the 7FP EU project School of the Future contributed to the process success, encouraging networking, periodical evaluation and reporting.

- Involving the school coordinator and staff in regular communication to reduce obstructions to delivery and improving safety measures.

- Occupants were involved in the periodical evaluation through questionnaires that assisted to drive the design choices.

- The Municipal in-house management and coordination, already experienced in other projects, favoured cooperation between the various stakeholders and helped solve unexpected issues.

- Individual skills of the decision makers and the exemplary role decided for the project allowed to overcome the initial target. For example, the introduction of the mechanical ventilation, unusual in Italy, will demonstrate the feasibility of the measure in relationship to the occupants' acceptability and behaviour.

- Four individuals as part of the project teamwho were committed to energy-efficient buildings

- Demonstration project for sustainable renovation (Building of Tomorrow)

- Political circumstances and the commitments made to financial support

- Mainly local or regional manufacturers and contractors were involved (close proximity of company Obermayr which renovated the façade).

- Highly flexible contractors.

- Experimental testing of the ventilation system in one prototype classroom

- Site tours to other schools to understand current practices

- Employment of a construction site coordinator

- Integral planning (simulation, analysis, optimisation)

- On-site meetings with people involved - Tenants created a wish list.

- Original project planned as simple maintenance, however, it quickly became obvious that extensive renovation would result in a reasonable payback period (energy savings versus investment)

Høje-Taastrup
- A technical advisor working on another project started the discussion about the optimal energy solution and airtight buildings

- Economic calculations on energy savings / investments for two scenarios were performed, i.e. upgrading to current building regulation requirements and to Passive House level. The Passive House level was chosen for the thermal envelope.

- Focus on energy savings in the media and other places was a driver.

- The value of buildings in the municipality is of high importance, i.e. a renovation will maintain or even increase the value of a building.

- The municipality has its own «campaign» in the «Klima Kommune» (Clima municipality) which sets goals for energy efficiency in public buildings.

- The process was optimized (which will be beneficial for the upcoming twenty renovation projects of similar kindergartens within the municipality). 


\section{MONASTERY}

Franciscan Monastery,

Graz, Austria
- The conservation and preservation of the building based on the master plan for the implementation of a zero-emission monastery reflects the attitude of the order in terms of integrity of creation.

- Historic buildings have to be made fit for the future, requirements for renovation have to include environmental and energetic aspects as well as architectural aesthethics: «Ecological aesthetics» are at the heart of the overall master plan for the renovation.

- The monastery aims to produce enough energy to meet its own energy requirements, in order to reduce costs for heating. This has been realized by reducing the energy demand of the building and by installing renewable energy systems. The monastery has become a "prosumer», generating more energy than it requires.

- Improve the functionality of the existing building to include meeting rooms, conference centre, event rooms, etc.

- Improving indoor comfort in winter as well as in summer.

- A person with a clear vision, firm conviction and convincing manner - A monk responsible for the whole refurbishment process and a personal passion for sustainable solutions.

\section{SUMMARY OF DRIVERS (number in parenthesis indicates in how many cases this was identified)}

Drivers for initiating renovation

- Request by tenant / focus on long term client retention/ end of lease contract

- Poor indoor comfort / unattractive façade

- Need to co-locate organization

Human and organizational drivers for increasing ambition level of the project

- Responsibility of their practices on climate change / company policy / image

- Enthusiastic individuals

- The experience and support of the architect/technical advisor/facilitators

- Involvement of top management

- The will to learn and to be a frontrunner

- Employment of a construction site coordinator

- Involvement of occupants

Economical drivers for increasing the ambition level of the project

- Reducing / eliminating energy costs

- Use of grants to give prestige and better economic viability for the project

- Increase the value of a building

Process drivers for increasing the ambition level of the project

- Strong focus on monitoring during the process as mean to increase ambition level

- The building was empty, which was an opportunity to make a thorough renovation

- Informal and open decision making processes built on trust between the main actors

- The prestige of the project creating strong commitment from all project participants

- The process was optimized and planned integrally

- Mainly local or regional manufacturers and contractors involved which were highly flexible

Other external drivers

- The holistic and open approach of the rating scheme (BREEAM)

- Focus on energy savings in the media and other places 


\title{
4.5 Most important barriers for ambitious energy upgrading
}

\author{
PROJECT \\ IMPORTANT DRIVERS
}

\section{OFFICE BUILDINGS}

IAG House, 388 George

Street, Sydney, Australia

- Potential disruption to the tenant meant that the major services refurbishment elemenst of the project did not proceed at the time
Science Montoyer, Brussels, Belgium

Boligselskabet Sjæelland, Denmark
- Insufficient technical experience of all parties involved on specific topics like air-tightness

- The lack of widely spread technical solutions

- The relocation of employees during the renovation of the building presented some problems, but these were overcome by the use of both other buildings and temporary pavilions placed in the parking lot in front of the building.

- During the renovation of the facade asbestos was found in the existing structure. This delayed the renovation process and increased costs.

- The removal of some of the interior walls made it clear that the floor needed levelling in these areas; this was not foreseen and added to the cost of the renovation.

Solbråveien 23 in Asker, Norway

- Limited financial resources and no signed contracts

- No local installers of the Schüco system were available or willing to take on the challenge of this project. MB therefore had to search for suitable contractors abroad.

Norwegian Tax Administration Building

- The need to relocate to temporary offices was a significant challenge. If it had been necessary to also relocate the data centre, it is likely that NTA would have chosen another landlord. It is also a important question for Entra whether they then would have been able to renovate the building to such a high standard.

- Lack of knowledge on the tenant's part in combination with imprecise information from the landlord and consultants regarding the consequences of increasing the energy standard of the building. The tenant expected that the indoor comfort would be poorer with the chosen solution. In particular, they worried about long delays in adjusting the indoor temperature.

- NTA could not accept an increased rent. As a public body they focused on efficient use of taxpayer money. It would also be a deviation from the tender.

- In spite of a fundamental idea of saving energy, other factors seems to be more important to NTA. If it hadn't been for Entra's new strategy to be a leader within the field of energy efficient buildings, and for the motivation and knowledge of some of the individuals involved, this could have reduced the ambitions of this project.

- The tight time schedule made it difficult to consider the consequences of the new proposal. But due to intensive work by the consultants and the increased involvement of the top management this barrier was overcome.

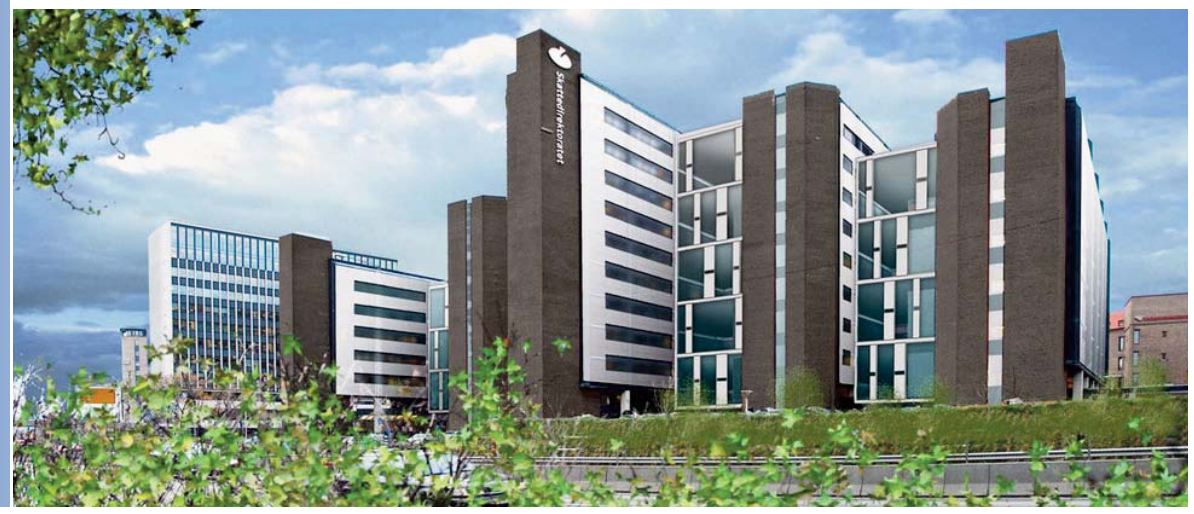

Norwegian Tax Administration Building - LPO artkitekter, Norway 


\section{MIXED OFFICE, RETAIL AND SERVICE BUILDING}

Rådhuskvartalet in Kristiansand, Norway
- Complexity of the project

- Protection of the historic elements of the building

- Lack of existing examples to be replicated

- Issues discovered during renovation which lead to a change in plans

- No previous experience with BREEAM (and Norwegian version was not ready at the start of the project) led to frustration and increased planning costs.

- The administration suggested a less ambitious solution in spite of their membership in "Cities of the Future». This shows that other factors often dominate the decision making process. In this case the politicians wanted a more ambitious solution.

\section{SCHOOLS/KINDERGARTEN}

"Tito Maccio Plau to" School, Cesena, Italy

- Adapting the execution phase to meet the schools ongoing functional requirements and limiting interference with existing functions was challenging.

- The project costs increased as a result of adjusting the project plan to ensure ongoing school functionality during the project execution.

- During the construction phase some barriers resided in product supply (suppliers went bankrupt, delays in payments and poor quality workmanship) due to the financial crisis affecting the sector, as well as the summer vacation period of dealers / suppliers.

- Limited economic resources in the Italian public authorities.

School in Schwanenstadt, Austria
- Lack of experience with this kind of renovation / energy standard.

- Prejudices and skepticism among decision makers.

- Unforeseeable problems relating to previous damage, and old or non-existant plans resulting in decisions having to be taken very quickly. Decision should have been made in advance.

- Individual production on-site (sanitation, wet installations)

- Occupancy during construction resulted in lack of attention and low levels of concentration of pupils. Relocation to a nearby facility would have been more suitable.

- As a public building tenders had to be invited publicly, but only a few enterprises had experience with such complex and innovative renovations. Criteria for chosing a tenderer and charging someone with construction works needs to consider this.

- Convincing the city council to go beyond regular maintenance and implement an extensive energy renovation, i.e. documenting the fact that this was indeed the right way to go, was the largest barrier.

- The relocation of the children during the renovation of the façade of the building was a problem for many parents and a speedy process was necessary for this part of the renovation.

- Separating the building site from the kindergarten activities also presented a challenge, i.e. safety for the children. This was solved by sealing off parts of the kindergarten surroundings.

- A harsh winter delayed the building process by several months

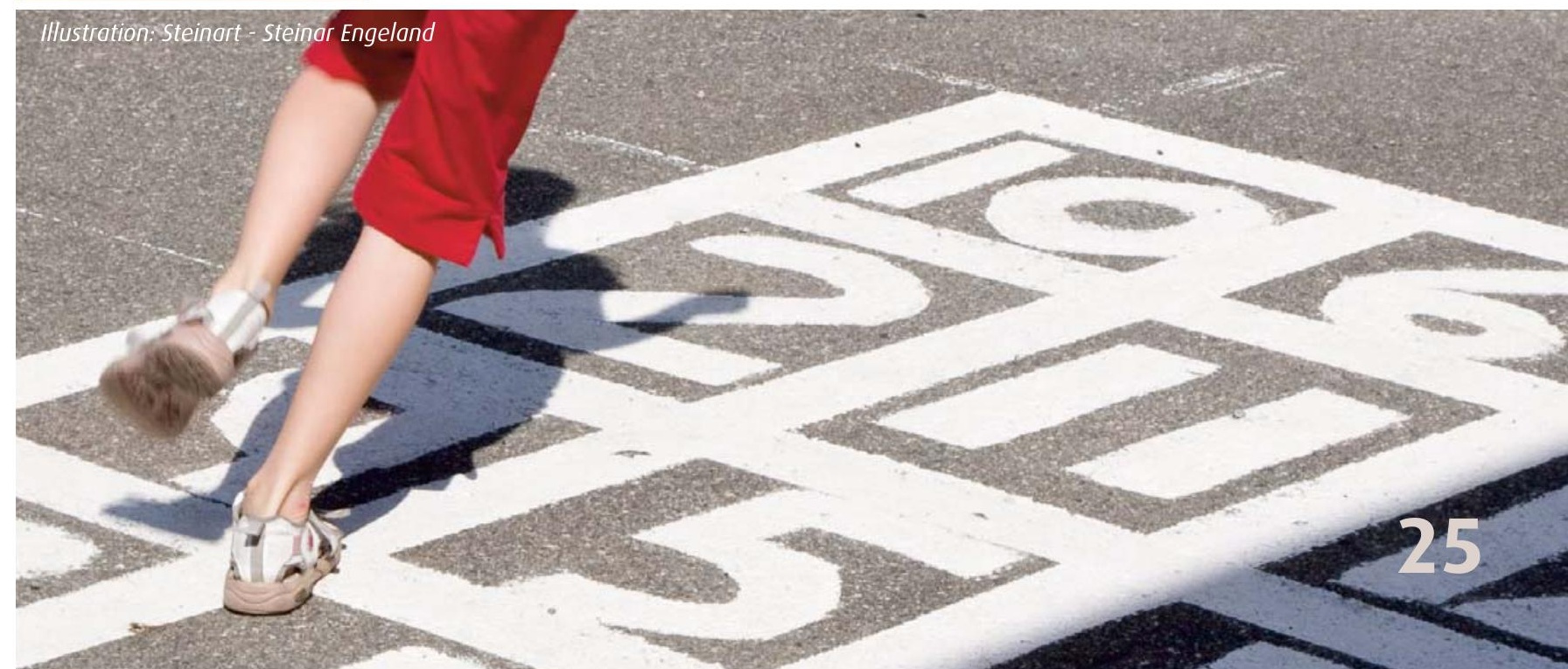




\section{MONASTERY}

Franciscan Monastery,

Graz, Austria
- The project had two different public authorities responsible for the building permits (the Building Authority of the City of Graz and the National Heritage Agency) and in addition two further public committees (the committee responsible for the conservation of the old town of Graz and ICOMOS - representing the UNESCO World Heritage Committee) with consultative function in the decision making process of the building permits.

- The position of the monastery in the «heart» of the city of Graz, which is part of a protected ensemble (regional law) and part of a UNESCO world heritage site (international requirements).

- The status of the monastery as a listed historic building (national law).

- Special requirements caused by the protection of historic roofs in the center of Graz: the installation of the solar collectors resulted in the main conflict with the public authorities and committees.

- Overall lack of experience for all parties involved with this innovative kind of desired energy standard in a listed historic building within a protected ensemble.

\section{SUMMARY OF BARRIERS (number in parenthesis indicates in how many cases this was identified)}

\section{Economic barriers}

- $\quad$ Limited financial resources and no signed contracts;

Maintaining originally agreed rents in upgraded premises

High investment cost

- $\quad$ Need to relocate building occupants during the renovation process

\section{Time constraints}

- $\quad$ Delivering projects against tight programmes

Technical constraints

- Poject complexity

- Heritage protection of historic sites

- Constraints due to the need for continuous functionality during the renovation

(occupancy, current use, safety)

Need for convincing arguments for NZEB renovation

- Convincing decision makers to go beyond regular maintenance and implement an extensive energy renovation

Lack of experience/competence and limited availability of technical solutions

- Insufficient technical experience of all parties involved on specific topics like air-tightness

- $\quad$ The lack of well known and wide spread technical solutions

- Lack of knowledge on the tenant's part

- Imprecise briefing information from the landlord and consultants

- No previous experience with BREEAM led to frustration and increased planning costs.

Lack of experience with this kind of renovation/energy standard.

Prejudices and scepticism.

Lack of previous examples to be replicated

- $\quad$ Difficult tendering processes with public buildings: definition and inclusion of criteria that enable clients to chose tenderers that are capable of performing the works (best price is not enough)

Physical challenges during renovation

- Presence of asbestos in the existing structure causing delays and increasing costs.

- Issues discovered during renovation which lead to need of change in plans such as poor structure, making after demolition and the like

- Unforeseeable problems relating to previous damages, old or non-existing plans.

- Delays affecting product supply during holiday periods

- Weather conditions casuing delays to construction such as harsh winter, rain, heat etc

- Renovation work disturbing tenants including lack of attention and low level of concentration of pupils. 


\subsection{Main lessons learned from studied decision making processes}

\subsubsection{Summary of drivers and barriers}

Figure 12 shows how the different drivers and barriers in the studied projects occur in different phases of the process. With the exception of IAG House in Sydney, all projects have in common that there are reasons other than the environment that initiates the process. The most common for these cases is that the building needs some form of refurbishment.

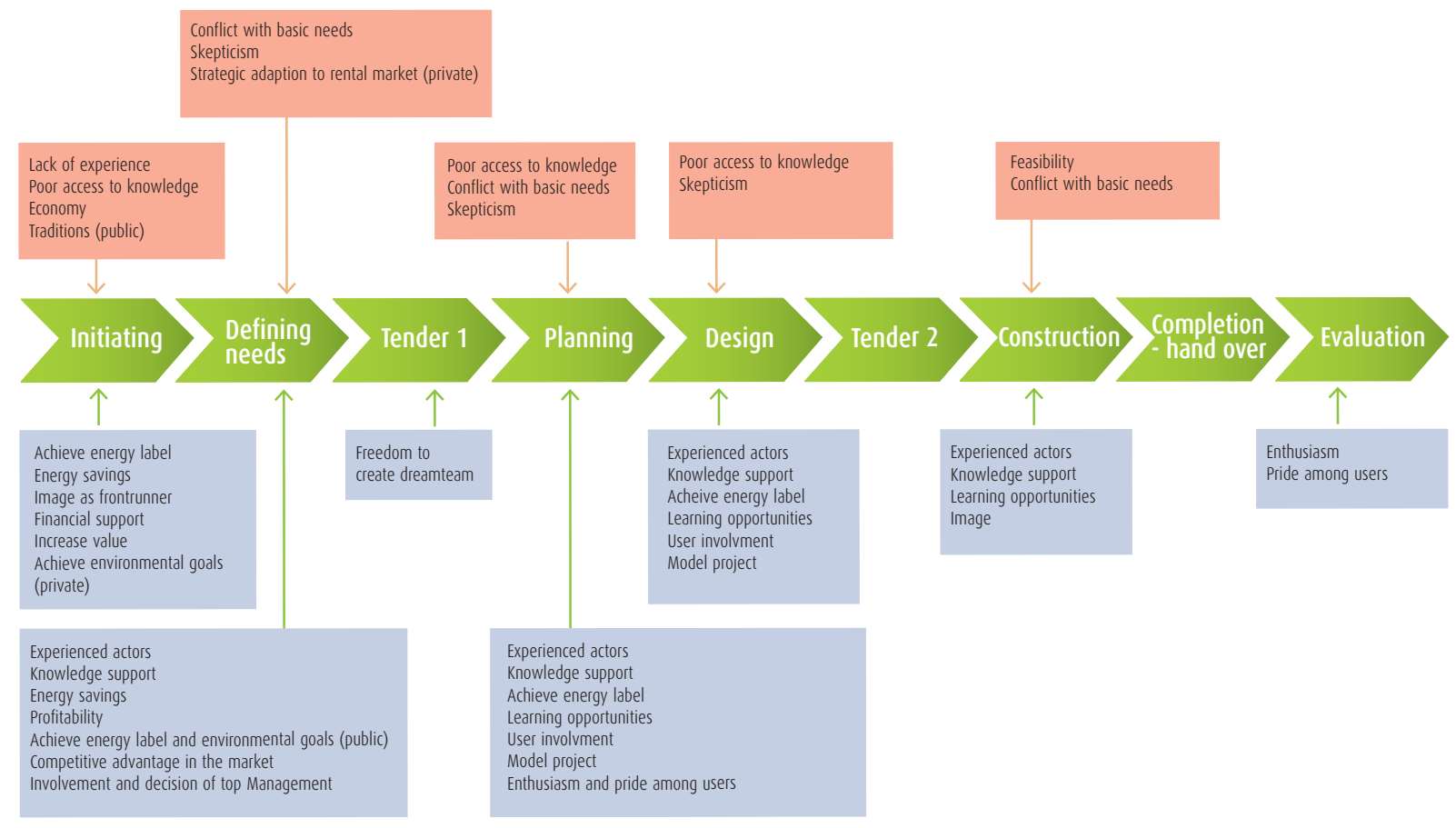

Figure 12: Barriers and drivers throughout the process

\section{The initiating phase}

\section{Drivers}

The most important drivers identified for increasing the ambitions on energy savings in the initiating phase are; to achieve an energy label/green building rating, reducing costs through energy savings, earning an image as a sustainable leader, or to obtain financial support. In the private sector one important driver as well was to achieve environmental goals. Several of the cases involve municipalities with clear environmental objectives. Yet this is not a important motivating factor in these projects in the first phase. Possible reasons for this is discussed as part of the barriers in the initiating phase. For the bigger companies it seems like this is a question of harmonizing corporate actions and facilities with the environmental standard/goals of the organization (IAG, House). An attractive location has a market for tenants who set environmental demands. The fact that the ambitions for energy saving in building projects are supported and calculated as profitable through the use of advanced planning tools, gives the developer the financial security they need. To achieve environmental targets therefore remains as an important driver throughout the project lifecycle. The Science Montoyer, Brussels, and Solbråveien 23 case studies show the same mechanisms. 


\section{Barriers}

The most significant barriers common across all projects are the lack of experience, poor access to knowledge, concerns about the economy and scepticism from users and decision makers. Looking at the barriers in the initiating phase in the case of The Kindergarden in Denmark, and Solbråveien 23, Norway, the crucial barrier in this phase was an easy access to knowledge. This lack of good examples often traps new projects in the old traditions of planning. The case of the public kindergarden in Denmark shows that these factors overshadow the general environmental goals of the "Klima Kommune" (Clima Municipality). There is also a parallel to the school in Cesena, Italy, where the poor economy is pointed out as an important barrier, but there is an awereness of the possibility of economic support through grants and other funding. It is a paradox that this also occurs in the municipalities that have set clear targets in climate and environment. It will be important to find out why this happens, and what can be done.

We question whether the culture of public administration is limited to think of traditional solutions as they have a strong focus on the reduction of the high initial investments costs.

\section{Defining Needs Phase}

\section{Drivers}

Important drivers during the needs definition phase are: having experienced stakeholders and/or knowledge support, achieving energy savings, improved profitablility, the ambition to achieve a target energy label/rating, and to obtain a competitive advantage in the market. When public projects described above were supported by knowledge while defining the needs, it showed that economic concerns could be overcome whilst achieving environmental goals. It is possible that some of these projects would not have been implemented with the same ambition, if they had not received such knowledge support and utilized experienced stakeholders during this phase. When considering the circumstances and input that enable successful outcomes in the case studies it is obvious that many potential projects may never get considered.

\section{Barriers}

As discussed in the introduction, it is typically needs other than energy savings or environmental outcomes that initiated the upgrade. It can be the need for increasing maintenance, lack of space, poor indoor air quality, etc. If there is uncertainty and questions about setting higher ambitions than the original requirements, this will become a barrier with scepticism from users and decision makers. In the needs definiation phase, it must therefore be made clear that the competing needs can be combined in the final solution to achieve high ambition outcomes.

Particularly in cases with a private developer, we see that in this phase it is important for the landlord to ensure that the tenant's needs are appropriately captured and interpreted.

\section{Tender Phase}

\section{Drivers}

The case studies demonstrate that the freedom to put together a "dream team» is a key driver in the tender phase, e.g. IAG House and Solbråveien 23. This allows clients to choose companies they have experience with, and companies which have worked together on similar projects before. This is less predictable in public sectore projects where work must often go through an open tender process. One interesting example is from the Solbråveien 23 case where the main contractor was «Moderne Byggfornyelse AS (Modern renewal solutions)» who has a strong focus on energy efficient solutions. They target projects who they are able to influence to choose good solutions. As a consequence they avoid public projects, which they have experienced often have a one-sided focus on price. 


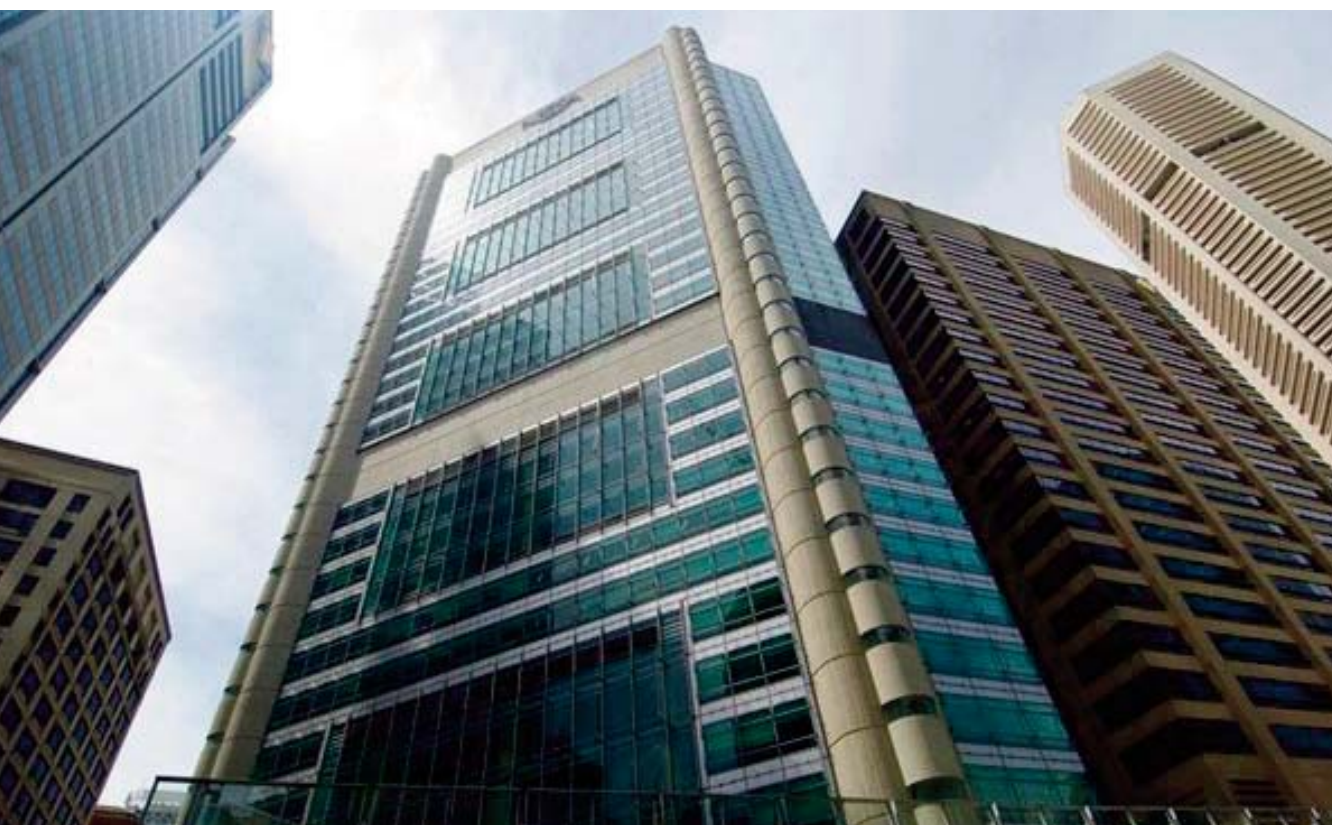

IAG House, 388 George Street, Sydney, Australia. www.architectureanddesign.com.au
To avoid this becoming a barrier, it is important that the project specifications in the tender are such that price is not the only criteria and that other factors such as previous experience, technical knowledge, delivery methodology and project team members have equal weighting. Furthermore, in public sector projects, prequalifing tenderers based on experience and approach to the project along with potential value add and innovation can reduce the influence of price in the decision making process.

\section{Planning Phase}

\section{Drivers}

Experienced team members have great strengths to contribute in the planning phase of a project as well. Additionally or alternatively, the team needs knowledge support to create the best project plan to achieve the desired energy label or energy target.

The case studies also show that learning opportunities are an important driver for those team members who do not yet have experience in delivering high ambition projects such as NZEB. One good example of this is the Science Montoyer case study. Despite a lack of experience in high ambition projects, the company-wide decision to transform their portfolio towards sustainable construction made them eager to learn. For that reason, not being selected in the 2007 BatEx competition intrigued them, more than it did discourage them to resubmitted their application. In the case of Boligselkabet Sjæelland, the learning process resulted in a new strategy in planning. The experiences can be applied for upgrading of the residential buildings (about 13,000 homes) which the company is managing.

As mentioned in the previous section - "defining needs», scepticism from users and decision makers can be an major barrier to implementing high ambition targets. Some of the case studies show how this is handled in a good way by involving users and decision makers in the planning phase. For example, the case study of the school in Schwanenstadt, where a site visit was organized for decision makers, and testing of a classroom was undertaken for a full year as part of the process. In the example of Rådhuskvartalet i Kristiansand scepticism turned into enthusiasm and pride among the users when they felt that they were heard by the design team, and received answers to their concerns.

\section{Borriers}

Poor access to knowledge is the most significant barrier identified in this phase. We think in this context the lack of knowledge about what is possible, and who can help limits the innovation that is brought to the design. Also in this phase, conflict between the basic needs initiating the renovation and the vision of higher ambition, combined with scepticism from users and decision makers are identified as barriers in the cases studied. The case studies demonstrate how these barriers can be dealt with. A key finding from the 
case studies is that the developer should consider the extent to which these barriers will exist in their project in the initial phase of the project and engage the design team in identifying ways to deal with them as early as possible.

\section{Design Phase}

\section{Drivers}

Experienced actors, knowledge support, learning opportunities, user involvement, examples and testing are consistently identified as the important project drivers through the case studies. A good example of knowledge support is from the Science Montyer case study. The feedback was provided by the Brussels facilitator, mainly concerning meeting summer comfort conditions. The building, designed as a standard office building, had an almost entirely glazed façade, raised floors and lowered ceilings. This would have led to a high cooling demand. Therefore BatEx (the funder) did not select the Science Montyer renovation due to concerns around the summer comfort conditions within the building. Although some might consider it as a major barrier, it was seen as a chance to improve (for details see annex 6).

\section{Barriers}

We find the same barriers in the design phase as in the planning phase including poor access to knowledge, and scepticism from users and decision makers. The reason for the rejection by Batex go right into the core of the concerns of the users in some of the other case studies. The objections from users and decision makers are perceived as barriers in all the cases. The example above shows that it is important to also have a critical point of view to secure the result. A belief that all new environmentally friendly solutions are good solutions can be naive.

\section{Construction Phase}

\section{Drivers}

Experienced teams/actors, knowledge support, learning opportunities are particularly important drivers in this phase.

Knowledge support plays a major role when project participants have less experience in delivering high ambition projects. In one example (Science Montyer case study) the architect had a lot of experience with renovation projects in Brussels, and for a long time had been interested in bio-climatic architecture. He

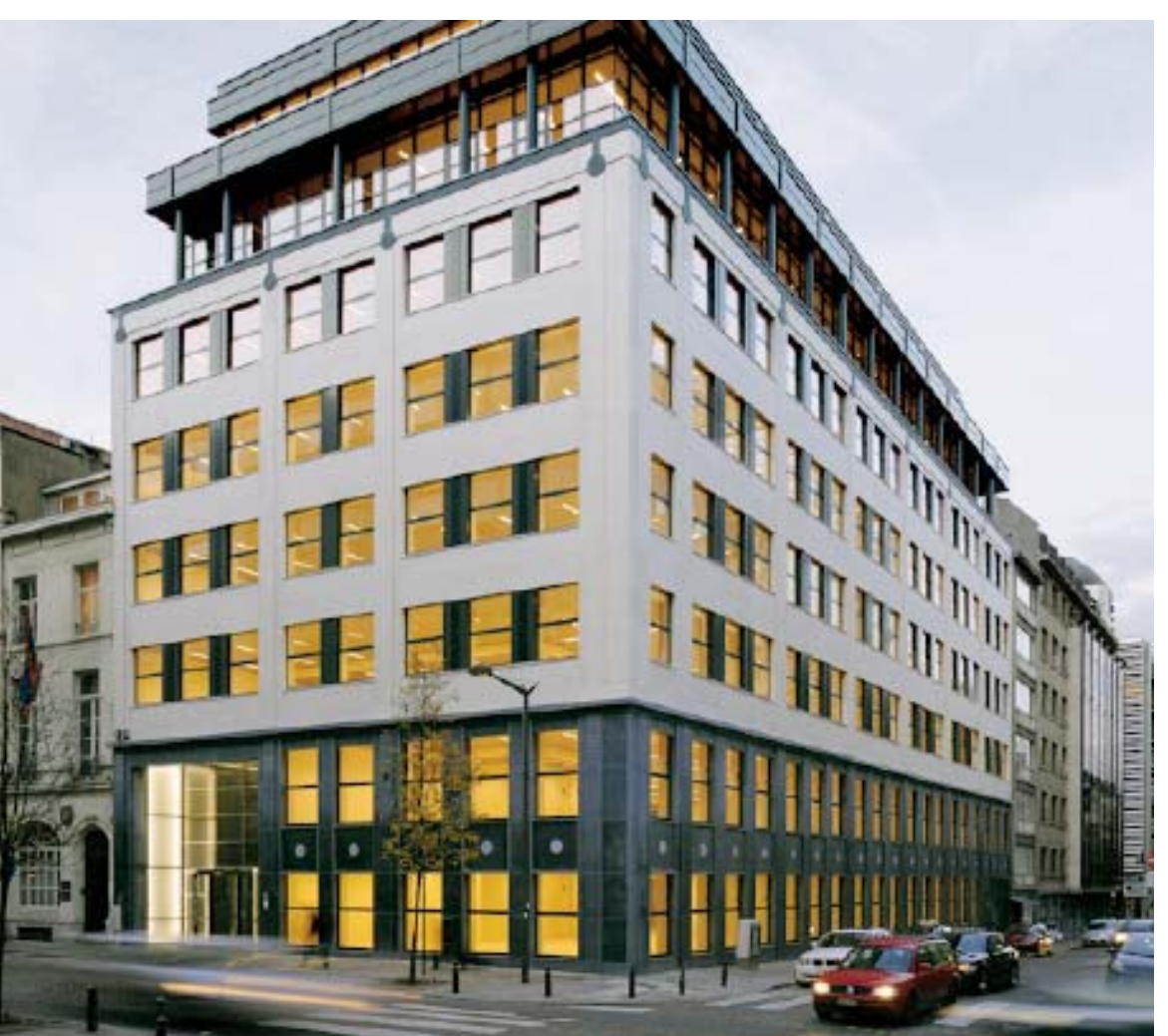
used a hands-on approach towards quality control for many years, spending at least one hour every morning on the building site, monitoring the execution and explaining to workers the importance of their work and the consequences in achieving the final project goals. of course one shall also be aware that the craftsmen executing the work often have expertise developing alternative and efficient solutions through on site experience rather than just from what is planned from a theoretical perspective. The actors in the Solbråveien 23 case have experienced the advantages of such a pragmatic process. 
For companies that perform construction, the opportunity to learn through such projects is a common driver. This is because they believe they will be more likely to secure future projects in a projected growing market of energy-ambitious upgrades.

\section{Borriers}

During the construction phase, the main challenge is the availability of the right building materials and available expertise to perform the job.

If any conflicts with other needs are not taken into account earlier in the process, these barriers can still cause opposition to the project (refer to previous comments). There may also be unforeseen challenges during construction that alters earlier assumptions. That may set environmental goals against other important parameters in the construction project. Like in the Solbråveien 23 case it is important that every issue is solved, carefully looking for measures that could also bring energy savings.

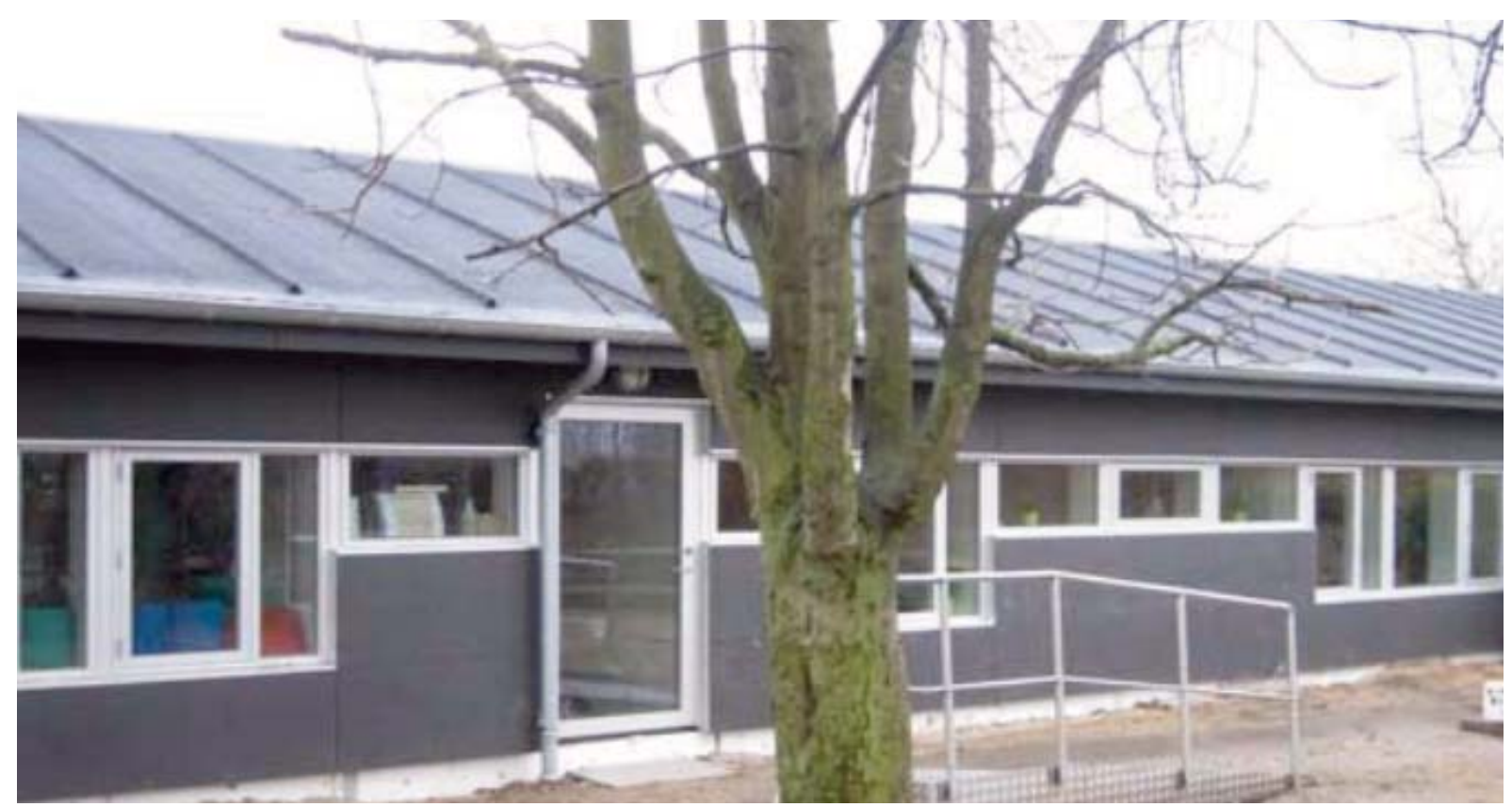

Danish kindergarten in Høje-Taastrup. Photo: Høje-Taastrup municipiality.

\section{Completion - Handover Phase}

In this work, we have not identified specific drivers and barriers related clearly to the Completion - Handover phase. With regard to drivers, they are closely related to the drivers identified in the evaluation phase. Considering barriers, time is an important performance parameter. For most projects it is important that the building is ready on time. For example, in the kindergarten Høje-Taaastrup case study, the relocation of the children during the renovation of the façade of the building was a problem for many parents and a speedy process was necessary for this part of the renovation. Harsh winter weather during the construction period delayed the building process by several months impacting the families. The need of a speedy process combined with the lack of experience of the project team in such high ambition projects, could easily have contributed to the owner choosing a more conventional solution with which they had more experience and which would have provided a more predictable process. 


\section{Evaluation Phase}

\section{Drivers}

Enthusiasm and pride among users and actors involved is clearly important. If the result is good, this positive experience is a very important driver for future projects. Looking at the Schwanenstadt case, the level of user satisfaction was evaluated after completion. Right after the renovation was completed the satisfaction level was 80\%. In the second year the level increased to 85\% which shows a high satisfaction and excellent quality of the building materials used. According to Mayor Karl Staudinger, the interest for visits was (and still is) high. Even 2013, he was invited to hold presentations and to present the building even though the building was completed in October 2007. This shows how the example can become a driver in the initiating phase of new projects.

\section{Barriers}

Looking at the negative feedback in the evalutation of the case studies, a common theme is challenges associated with construction work disturbing tenants (for instance lack of attention and low level of concentration of pupils, safety for children and/or staff etc.). It can be argued that this is general challenge facing any renovation of these type of buildings. There is little correlation between these particular challenges and the level of ambition set for environmental benefit and energy savings on the project.

\section{Operation Phase}

For the operation phase of the building, it is important to provide a handbook or user guide for users where they can learn about the new technologies that have been installed, e.g. ventilation, and in particular how to operate the building correctly especially when the users have a level of control over the operation of their space.

Commissioning and tuning is a critical to the successful implementation of new technologies (and old technologies) and poor commissioning is a major cause of problems during the operation phase. It is essential that time is allocated prior to handover testing and commissioning and then using the evaluation phase to gain feedback and insight from both users and building management systems to further tune and fault find systems, especially HVAC, lighting, controls and newer or innovative technologies. This will ensure that all systems are installed correctly and working as designed, e.g. solarthermal systems.

\subsubsection{Clear understanding and definition of needs}

Table 6 describes how each of the case studies have gathered a holistic understanding of the tenants' and owners' needs - which normally are more than only energy efficiency.

\section{PROJECT UNDERSTANDING AND DESCRIBING THE NEEDS}

\section{OFFICE BUILDINGS}

IAG House, 388 George

Street, Sydney, Australia
Project was initiated by the tenants, two sister insurance companies IAG and NRMA. This was due to their considerations of the effect of climate change on their business The ambition level was set by the tenants.

Relocation during the renovation was not considered possible, and the retrofitting strategies had to take this into account. 


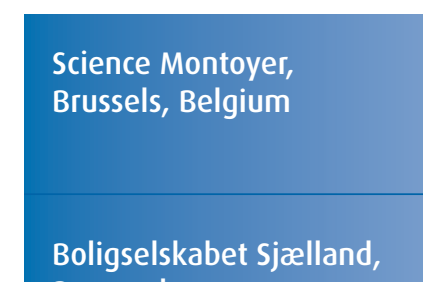

Denmark
Due to need for more space, the existing tenant made it clear four years prior to the end of the lease contract that they would not extend the lease. The owner therefore started to plan how to convert the worn out building into a highly attractive premises for new tenants and at the same time meet very high sustainable standards.
Solbråveien 23 in Asker, Norway

Norwegian Tax

Administration Building
The primary reason for this renovation was a need for more space, improved indoor climate, and upgrading the facade. A lot of effort was spent on convincing the representative board to set high ambitions for energy savings.

In this case there was not a clear understanding concerning an ambitious renovation. The real estate management did not initially have a specific strategy related to energy and sustainablility measures. The most important driver in their situation was to get a long term tenant. Through a close network amongst the project participants, the main contractor convinced the owner that a focus on environment and energy savings would be attractive in this market.

The project started as a tender with a description for premises to meet the Norwegian Level B energy label. The tenant wanted good levels of indoor comfort, balanced with reasonable rent as well as a building with the lowest possible carbon footprint. It was also important that the employees were relocated to attractive temporary premises during the renovation.

\section{MIXED OFFICE, RETAIL AND SERVICE BUILDING}

Rådhuskvartalet in Kristiansand, Norway
Having a high ambition renovation was not the fundamental need that started this project. But early on it became an important parameter.

\section{SCHOOLS/KINDERGARTEN}

"Tito Maccio Plau to" School, Cesena, Italy

School in Schwanenstadt, Austria
The initial target level was decided by the local Municipality. The final performance level achieved after the renovation increased and was advocated by the external consultants and by the in-house management of the various actors (including the occupants).
Danish kindergarten in Høje-Taastrup
Because of the poor building standard - especially the poor façade - and high annual energy costs, the school building in Schwanenstadt, which was built in the 1960's, needed a deep renovation. The renovation in 2006/07 was submitted as a research project in the Austrian research program «Building of Tomorrow» and demonstrated the first refurbishment of a non-residential building achieving Passive House standard with prefabricated wooden façade elements and a comfort ventilation system in Austria.

The goal was to increase comfort for pupils with regard to thermal comfort and fresh air, as well as improve the use of daylight.

A leaking roof, worn out windows and a building suffering from uncomfortable draught were the main reasons for renovation. Achieving energy savings and good environmental outcomes were introduced later. 
Franciscan Monastery, Graz, Austria
On an operational level the durable reduction of overall energy consumption and of energy delivered by the local utility supplier was the main trigger for this project (the monastery had the aim to be a "prosumer»).

On a practical level there were also needs based on functional requirements (new kinds of rooms, modern/adequate infrastructure within the rooms) as well as changing behavioural aspects. All in all, the terms of use of the monastery had to be improved to meet more modern uses and needs.

At construction level there is an ongoing need to maintain components which are exposed by mechanical, chemical, thermal, hygric etc. influences. This also related to the historic dimension of the needs: the continuous, but cautious adaptation of historic buildings to current and upcoming requirements guaranteeing a satisfactory utilisation of the building and its rooms for its owners or tenants.

\subsubsection{Value propositions which fulfill customer needs}

Table 7 describes the value propositions in the case stories.

\section{PROJECT VALUE PROPOSITIONS}

\section{OFFICE BUILDINGS}

IAG House, 388 George

Street, Sydney, Australia

Science Montoyer,

Brussels, Belgium

Boligselskabet Sjæelland, Denmark

Solbråveien 23 in Asker, Norway

Norwegian Tax Administration Building
Measures proposed would upgrade the building NABERS rating from 2.5 to 4.5 stars (max 6). All measures were technical (chillers, water pumps, fans, cooling towers and lighting) and thereby avoided retrofitting of the building envelope which despite its age was in good condition and had good thermal and energy performance. Any façade upgrade would also have a significant impact, disturbing and dislocating the tenants during retrofitting. The proposed solution also gave the best IRR for a reasonable capital expenditure.

The first proposal did not meet the criteria of BatEX funding which was a goal for the owner. Two years later a new and more energy efficient solution was developed and succeeded to achieve the funding. Other smart solutions were developed, including changing the entrance to an alternative and more prestigious street frontage, thereby increasing the value of the building.

The project had a strong focus on energy efficiency to start with. The company wanted a solution that would strengthen its green profile. 3D-modelling combined with technical information; convinced the representative board that high ambitions would be economically viable.

After the main contractor had convinced the property owner that a high ambition renovation was the right way to go, it became apparent that the facade of the building also needed a facelift in order to fulfill all of the customer needs. This resulted an even more ambitious retrofit solution.

The solution offered as response to the tender included a specified energy standard, relocation of all clerks to very attractive offices in another part of the city during the renovation and a new floor layout which was very space efficient. But most important; the data centre could remain in the building during the renovation which meant a substantial cost reduction for the tenant.

After the contract was signed, the landlord proposed to increase the energy ambitions of the project by raising the standard to energy class $\mathrm{A}$, in order to underpin both the owner and tenant organizations sustainability strategies. 


\section{MIXED OFFICE, RETAIL AND SERVICE BUILDING}

Rådhuskvartalet in

Kristiansand, Norway
The fundamental needs that initiated this project were considered the most important for the future users of the building. Therefore there were concerns that a high ambition renovation would be in conflict with fulfilling those needs. Involvement of the interested parties led to an exchange of needs and information and brought all actors on board with the project ambitions. This in turn ended the scepticism into pride and enthusiasm.

\section{SCHOOLS/KINDERGARTEN}

"Tito Maccio Plau to» School, Cesena, Italy

School in Schwanenstadt, Austria
A poor economy and concerns from the users in guaranteeing continuous functionality to the school for lessons, facilities and office activities. This functionality had to be dealt with in order to fulfill the "customers» (teachers, parents, pupils, decision makers) need.

There were concerns regarding the proposed mechanical ventilation system. This was handled by the decision-makers in the municipality visiting other schools which already had experience with such ventilation systems. In addition to this, it was decided to test and evaluate the ventilation system in one prototype class-room for one year. This way it confirmed that all theusers needs would be fulfilled.

During construction works a construction site coordinator made sure that all needs were considered. Users were offered to participate in meetings and to compile a list of wishes.

Danish kindergarten in Høje-Taastrup

High ambition renovation became an option when it became clear that it was possible to achieve better energy and environmental outcomes while fulfilling the needs that originally inititated the renovation planning.

\section{MONASTERY}

Franciscan Monastery, Graz, Austria
In relation to a standard refurbishment of a historic building, the value proposition of the refurbishment is a long-lasting reduction in heating costs and high degree of energy self sufficiency.

Table 7: Value propositions

\subsubsection{Passionate and committed persons}

Table 8 describes the commitment of key persons in each of the case stories studied.

PROJECT COMMITMENT OF KEY PERSONS

\section{OFFICE BUILDINGS}

IAG House, 388 George Street, Sydney, Australia

Science Montoyer, Brussels, Belgium

Boligselskabet Sjælland, Denmark

Solbråveien 23 in Asker, Norway
The client organizations had a clear commitment through organizational policies to deliver sustainable outcomes and promote low carbon initiatives. The consultant team provided strong technical evidence for the renovation through simulation and design.

Key persons approached this project as a learning experience.

Key persons in the company wanted this project to become a reality. Also the architect Charlotte Jakobsen Szøts was a driving force in finding green solutions. (Szøts was also engaged by the owner afterwards, and this project experience will be utilized in other projects. This company owns and manages about 13000 homes.)

A very convincing main contractor changed the approach of the whole project. The project provides a positive influence on the property owner for new thinking and strategies in the market. 
Norwegian Tax

Administration Building
All key stakeholders had individuals in their organisations who were very committed to making this project a success. Some of the individuals had a personal passion for sustainable solutions.

\section{MIXED OFFICE, RETAIL AND SERVICE BUILDING}

Rådhuskvartalet in

Kristiansand, Norway
In particular the Mayor played an important role insetting the ambition target. The majority of the city council supported a more ambitious project than was original suggested by the administration.

\section{SCHOOLS/KINDERGARTEN}

«Tito Maccio Plau to»

School, Cesena, Italy

School in Schwanenstadt,
Austria
Danish kindergarten in
Høje-Taastrup

\section{MONASTERY}

Franciscan Monastery, Graz, Austria
All key actors were very committed and the demonstration character of the project was extremely helpful.

Particular strength was found in the good network, "group game» between the actors and the communication with the school users.

The project had five individuals as initiators promoting a sustainable and energy-efficient building: Mayor Karl Staudinger, architect Heinz Plöderl, Christian Obermayr, head of an Upper Austrian timber construction company, Christoph Schloßgangl and Günter Lang, the latter affiliated to the Austrian Passive House association IG Passivhaus.

An architect working on a different project in the municipality started a discussion that soon made it clear that extensive energy renovation would result in an acceptablepayback time. The public management then had to convince the city council about this.
The main person to make this project successful has been a monk of the monastery and responsible for the whole renovation project. It has been his engagement, his persuasiveness and his endurance to bring this project to an innovative and outstanding result. In addition, there have been well-experienced architects and technicians to elaborate a promising master plan and to design and plan the respective renovation works.

Table 8: Commitment of key persons

\subsubsection{Involvement of multi-disciplinary teams}

Table 9 describes how multi disciplinary teams were involved.

PROJECT INVOLVEMENT OF MULTI DISCIPLINARY TEAMS

\section{OFFICE BUILDINGS}

IAG House, 388 George Street, Sydney, Australia

Science Montoyer,

Brussels, Belgium

Boligselskabet Sjalland, Denmark
The involved actors already had experience working together and had trust in each other. They therefore knew how to effectively interact and to contribute to good multi disciplinary solutions. Efficient and accurate simulation tools also play an important role by giving a higher degree of certainty in front of decision making.

The team was composed of people with a broad range of expertise.

The team consisted of actors that were comitted, with Dominia AS they also have experience in the team. 
Solbråveien 23 in Asker, Norway

Norwegian Tax

Administration Building
In this case there was a team which had experience from earlier projects. Therefore there was a fundamental trust even though this was a new experience for the property owner. In this case they also found that the craftsmen executing the work may realise better solutions than what is planned from a theoretical perspective.

Due to the size and complexity of the project, there were several experts involved in the process (from initiation to execution of the renovation). There was also a consulting board established with representatives from the tenant and owner, which instructed the hired external project manager.

\section{MIXED OFFICE, RETAIL AND SERVICE BUILDING}

Rådhuskvartalet in Kristiansand, Norway
The project had a highly respected internal project leader with good communication skills. The constructor also had experience building according to the passive house standard.

\section{SCHOOLS/KINDERGARTEN}

«Tito Maccio Plau to»

School, Cesena, Italy

School in Schwanenstadt Austria
The team included a broad range of expertise The involved actors already had experience working together and had trust in each other (Owner, energy manager, contractors). The involvement of the National Agency for New Technology and Energy (ENEA) and the monitoring within the EU project also resulted in a successful experience, achieving the highest target at low cost and the first POE results.

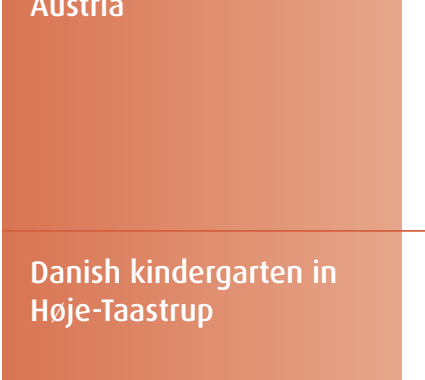

The project was submitted as a research project in the Austrian Research programme «Building of Tomorrow». A detailed study on how to achieve passive house standard was undertaken before construction works started. Also ecological materials and daylighting were considered. Ninety per cent of the investigated issues could be implemented in practice as well. One reason was the high commitment of the actors. For instance, the architect spent the first hour every day to partly inspect, and partly gain ideas from the construcion site.

\section{MONASTERY}

Franciscan Monastery, Graz, Austria
The project team had consulting engineers with experience and knowledge about Passive House.

\subsubsection{Organizational alignment}

Table 10 describes how each of the case stories studied are supported by top management and by their strategies/policies. PROJECT ORGANIZATIONAL ALIGNMENT

\section{OFFICE BUILDINGS}

IAG House, 388 George

Street, Sydney, Australia
The involved actors had a lot of experience with adapting and renovating historic buildings. Their interest was to find practical solutions for the comprehensive refurbishment of historic buildings which connects the highest possible degree of energy conservation and renewable energy supply with the challenges of protection of historic buildings/ ensembles namely authenticity and integrity. 


Science Montoyer,
Brussels, Belgium
Boligselskabet Sjæelland,
Denmark

The owner was very focused on sustainable construction, as this will increase the probability to get longer term lease contracts.

The decision was taken by the board of directors.

The company believed convincing the representative board was one of the biggest barriers to realizing the project. The support was given, and the company looked at this as a possibility to build a more green profile.

It became a strategy for the property management through this process.

Both the owner and the tenant had strategies which supported sustainable solutions. At critical parts of the decision making process, the top management in both organizations were involved and decided for increasing the ambition level.

\section{MIXED OFFICE, RETAIL AND SERVICE BUILDING}

Rådhuskvartalet in Kristiansand, Norway
The project was strongly supported by the city council. In line with the municipality's goal of being a frontrunner in the development of green energy and sustainable projects. Together this gave the administration and internal project manangement all the support they needed.

\section{SCHOOLS/KINDERGARTEN}

«Tito Maccio Plau to» School, Cesena, Italy

School in Schwanenstadt, Austria

Danish kindergarten in Høje-Taastrup
The Department for Public Works of the Municipality (building owner) was responsible for initiating and managing the project.

Cesena municipality is one of the signatories (2009) of the EU Covenant of Mayors and its Sustainable Energy Action Plan (SEAP 2011-2020) that contains ambitious energy efficiency targets for the public building stock. Prior to the renovation, the Municipality carried out an energy auditing campaign, identifying this school as particularly low performing. The opportunity for co-funding as a renovation demonstration case within a VII FP was extremely helpful to develop a new process, that will hopefully be replicated. The Energy Performance after the renovation overcomes the initial forecast, common practice of the Municipality renovation of non-residential buildings, as well as the Italian minimum energy performance requirements. This case study is currently being used within the Municipal, regional, national (e.g. PAEE and EED implementation) policy instruments as a best practice reference.

According to Mayor Staudinger the project was part of the coalition agreement between The Austrian People's Party ÖVP and the Green Party.

The municipality had it's own campaign as «Climate Municipality». It is intended that this project will become the standard for all remaining projects in the Municipality.

\section{MONASTERY}

Franciscan Monastery, Graz, Austria
The master plan regarding the zero-emissions-building was decided by the management of the Franciscan Order. 


\subsubsection{Summary of lessons learnt from decision making processes}

Considering Carlson \& Wilmot's five major factors [10], the case studies show that they are fulfilled to a high degree.

\section{Is there a clear need as a customer value?}

The «need» in the example project is a mixture of several elements:

- Physical need (something has to be done anyway; improve energy efficiency and realize non-energy benefits)

- The project should support the organization's overall strategy/policy (image, sustainability goals, good work environment)

- Good economy; return on invested capital

The highest energy efficiency ambitions were not always clear at the initial phase of the projects. This is especially the case in two case studies, the office building in Solbråveien 23, Norway, and the

Kindergarden Høje-Taastrup, Denmark. A clear need to increase the energy saving ambitions was not part of the building owners' value proposition when these projects first were initiated. For the municipality in Denmark this was a paradox, having not initially targeted environmental outcomes despite having stated general environmental goals as part of their strategy and guidelines and being a «Klimakommune» (a municipality with an expressed focus on CO2 reductions).

In the example of the kindergarten from Denmark there was an architect working on a another project for the municipality (meaning he was not directly involved in this project) who argued that aiming for a passive house standard would be economically viable. The administration in the Municipality took great interest in this proposal, and undertook analysis and documentation to convince the Municipality council. The end result was that all 27 kindergartens in the area would follow the passive house standard. In the Norwegian Tax Administration case, the long term tenant didn't want to commit to the most ambitious targets. They were worried there would be a negative focus on the costs of the project. But the property owner changed the plan during the process, increasing the ambition. In the Solbråveien 23 case study demonstrated that people in the network of the decision makers can influence ideas, finally increasing the ambitions for energy savings.

\section{Were there value propositions which fulfill customer needs?}

For the Kindergarden case, high ambition renovation became an option when it became clear that it was possible to achieve good outcomes, while fulfilling the needs that originally inititated the renovation planning. The original fundamental needs that initiated the Rådhuskvartalet in Kristiansand, Norway, project was considered the most important for the future users of the building. Therefore there were concerns that the high ambition renovation would be in conflict with fulfilling those needs. Involvement of the interested parties in the decision making assisted in exchanging ideas and raising the ambition levels whilst meeting the original needs. In the case of the Science Montoyer building, the first proposal did not meet the criteria of BatEX funding which was an original goal for the owner. In the end, however, the solutions offered values which fulfilled the original needs as well.

\section{Were there passionate and commited persons?}

There are several examples of passionate and commited persons throughout the case studies. The cases mentioned above are good examples where this was a crucial factor in the success of the project. In the Danish kindergarden example, it was a technical advisor working on another project who started the discussion about the optimal energy solution and airtight buildings resulting in achieving the passive house standard. In the case of the Monastery, the main person to make this project successful was a monk of the 
monastery and responsible for the whole renovation project. It was his engagement, his persuasiveness and his endurance to bring this project to an innovative and outstanding result. In the case of Rådhuskvartalet, the mayor, in particular, had an important role in setting the target ambition. Later, with support of the majority of the city council, they were able to achieve a more ambitious project than was suggested by the administration. In the same case a highly respected internal project leader with good communication skills played an important role in getting the best out of different interests in the project, instead of conflict.

In the various cases mentioned here, passionate people and experienced actors as part of, or creating good teams, contributed to the proposed solutions which offered values which fulfilled the needs of users completely in the end.

\section{Did the projects involve multi disciplinary teams?}

Adding up the actors that are involved and the passionate individuals that acted as project chamions, all cases succed in establishing good teams. The IAG, Solbråveien 23, Tito Maccio Plauto represent cases where the team is put together by actors who are used to collaborating, and also have some experience together.

\section{How was the organizational alignment}

Decisions in all cases were made at the highest level in the respective organisations: the board level, the board of directors, city councils, and for the Franciscan Monastery, by the management of the Franciscan Order. As commented earlier, in some of the cases the council (Kindergarden,Tito Macio Plauto) or the board (Boligselskabet Sjællland, Solbråveien 23) needed to be convinced first. But the success of the projects required approval at this level to enable the projects to take place.

\section{Short summary of chapter}

The case studies were selected precisely because they are good examples of energy ambitious construction projects. Through interviews with key stakeholders and exploring the barriers and drivers in various phases of these projects, one finds that even some of these projects were in "danger» of not being realized as energy efficient projects at some point. It is likely that many renovation projects, with the same opportunities and potential as these examples, never see the light of day. Much of this can be explained by the lack of knowledge of good examples, meaning that project teams never consider high ambition energy efficient renovation as a real alternative. Furthermore, throughout the various project phases there will be challenges and often these challenges deter project teams from attempting energy efficient retrofits.

This report points out how to get drivers to work to a projects benefit in each phase of the project. It also considers how to avoid or remove the barriers that may stop potential prosjects.

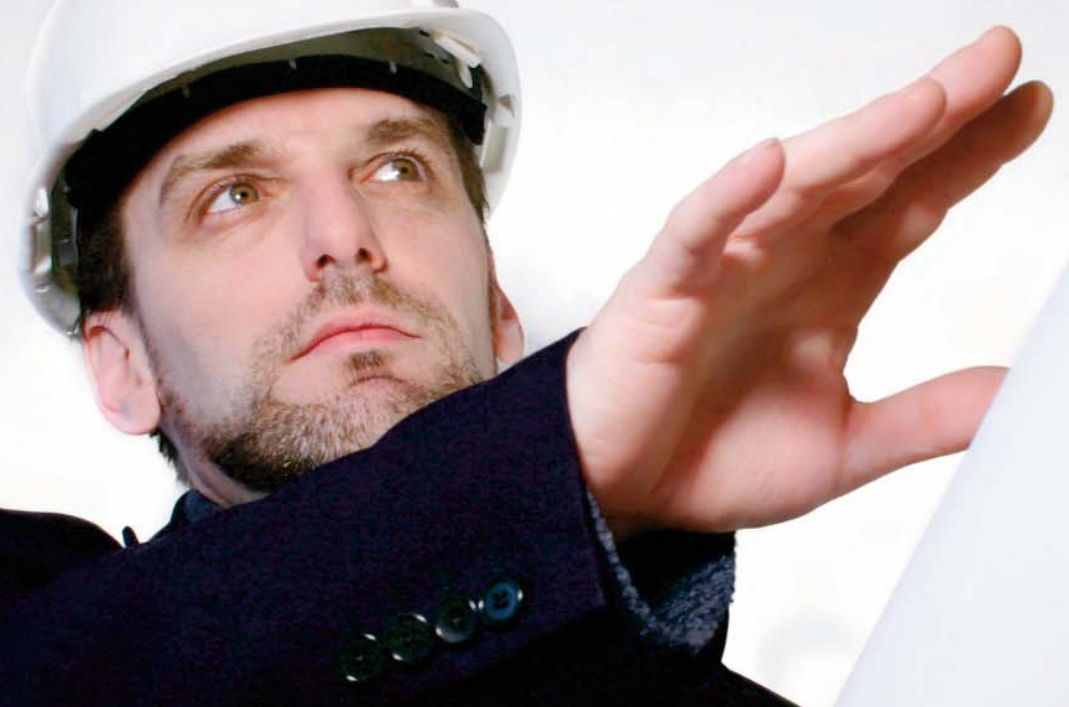




\section{ISSUES RELATED TO MODERNIZATION OF PROTECTED BUILDINGS}

\subsection{The conflict between preservation and change}

A large part of emitted anthropogenic greenhouse gases in the atmosphere results from human utilization of energy. A significant part of this energy is used to heat or cool our buildings, or for ventilation. In order to reduce the current energy demand of our buildings (and thus lower the greenhouse gas emissions), we need to aim for reduced energy consumption and an increased use of renewable energy sources. In new buildings, those aspects can be considered by respective planning, design, modern building services systems and technical equipment. The energy-related modernization of existing buildings, however, often requires substantial changes in the building structure and fabric. Each measure aimed at modernizing a building can also cause a change in the architectural expression. The desire to protect architectural or cultural value in historical buildings can come in conflict with such modernization efforts. This causes a conflict of interests, which subsequently generates an area of tension between the two goals, where negotiation and other solutions must be found. (see Fig. 13).

Humans of our modern age are shaped by thousands of years of cultural-historical developments.

Buildings have always been an essential expression of this development. By looking at buildings from the past, we can better understand political and societal contexts, technical improvements and we can better understand the living circumstances of former societies.

To protect these architectural «contemporary witnesses» and to give future generations the chance to reflect on their societal roots themselves are core objectives of our society.
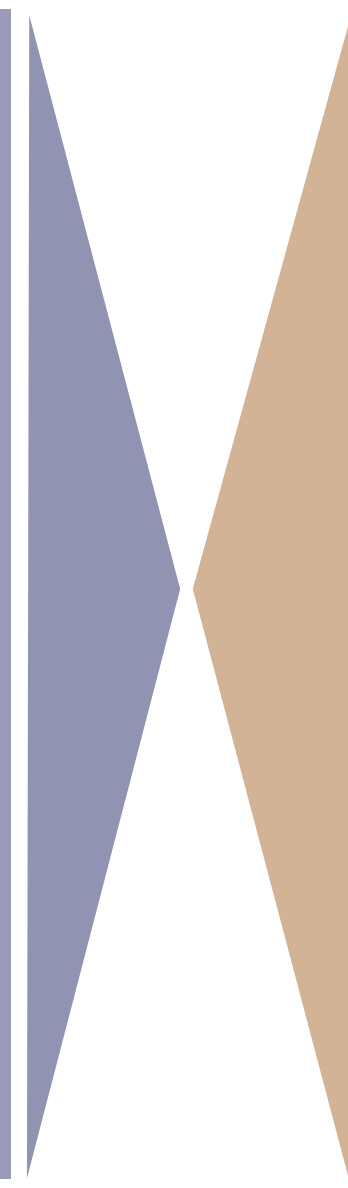

Due to human activities we must fear that our environment will soon face substantial changes. It is to be expected that the current, almost uninhibited, practice of emitting greenhouse gases, will cause massive changes in our climate. Future generations may lose their basis of existence due to our current actions. In order to secure the future of our society, we must reduce the emsissions of greenhouse gases. This is a core objective of our society.

(c) Graz University of Technology and Graz Energy Agency

Fig. 13: Conflict between preservation and change. Source: Denmalaktiv I [11]. 


\subsection{Monument protection and climate protection}

Both the discussion regarding the conservation of cultural-historical values as well as the discussion regarding the reduction of anthropogenic greenhouse gases have undergone a historical development. In the course of this development, the terms «climate protection» and «monument preservation / protection of historical buildings» have been identified and used as synonyms for these two issues. Both terms describe important concerns of our society and are (at least in most countries) enforced by law. Even though various national guidelines, acts and laws differ regarding their nomenclature and approach, the basic idea is the same. Subsequently, the terms monument preservation and climate protection will be used for the respective overall objectives (Fig. 14).

\section{Protection of historical buildings}

Authentic maintenance of the historical building substance

Monument conservation
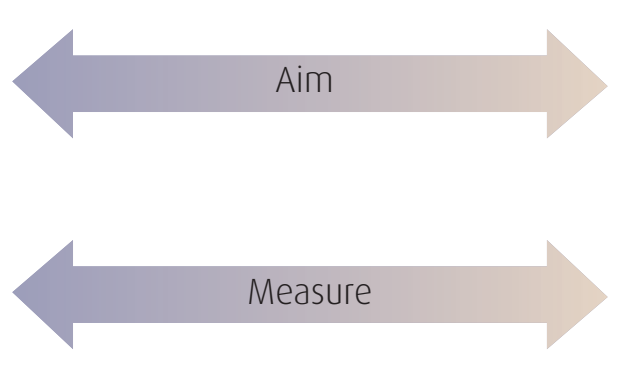

Since 1923 in Austria: Law for the protection of historical buildings
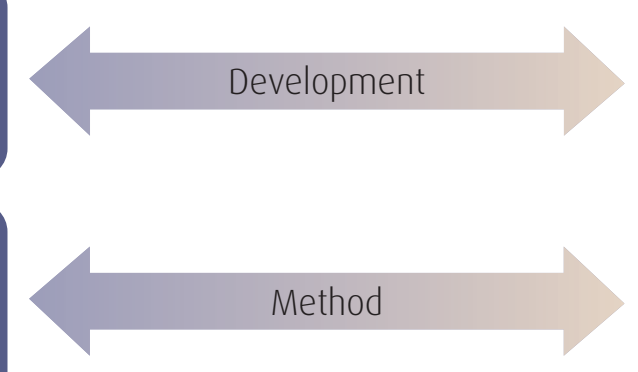
history, culture psychology
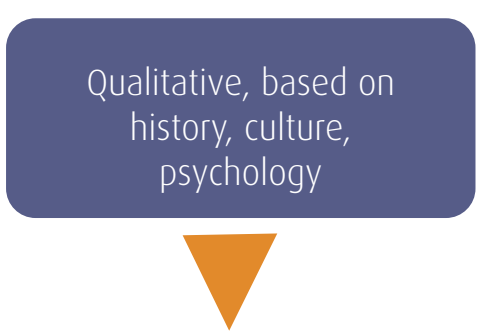

Law for the Protection of Historical Buildings, Law for Townscape Protection, Old City Preservation Law, UNESCO

\section{Legal Framework}

Reduction of CO2-emissions

Energy-related renovation

Keeling Curve since 1958 Kyoto Agreement in 1997

Quantitative, based on research results

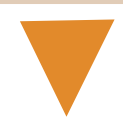

\section{EU-Directives}

Green Electricity Act Climate Protection Law Guidelines of Austrian Institute of Construction Engineering Subsidies

\section{Refurbishment Measures}


By looking at the various building cases, it can be shown that monument protection and mitigation of climate protection follow two rather different approaches. The clash of those two approaches causes a conflict of interest when it comes to decisions regarding structural or technical measures. Dealing with this conflict is made more difficult by the fact that monument protection is based on a qualitative approach, which integrates architectural, historical and cultural aspects and which is therefore difficult to evaluate with scientific standards. On the other hand we have the quantitative approach of climate protection, which claims a reduction of anthropogenic greenhouse gases. The associated methods rely on scientifically defined baselines, physical models and reproducible calculation methods.

\subsection{Results from the research project "denkmalaktiv |»}

The Austrian research project «denkmalaktiv I» [11] deals with the area of tension between climate change and monument protection for buildings on a technical as well as on a discursive level. The results show the following picture:

\section{A limited energy saving potential can be made available}

Even though - from a monument protection perspective - the conservation of the original condition of the building is the uncontested claim, it could be shown that there are energy efficiency measures regarding the building structure which are in line with monument protection. The intensity of these savings is, however, subject to great limitations. Plus-energy buildings are, due to the currently available renovation methods, technically feasible, but they would often result in deep changes to the architectural expression of a building, which contradicts the objective of the protection of culturally important buildings.

\section{Solar technologies are particularly problematic}

Particularly the use of solar technologies in protected buildings is seen critically by representatives of monument conservation. This is due to the fact that extensive collector fields have to be integrated into the building envelope, which causes a massive change of the formative expression of the whole building and therefore contradicts the protection objectives. A possible solution is the spatial separation of the protected building from the solar installations.

\section{Know-how deficits regarding the technical implementation}

The discussion has shown that the knowledge regarding energy-related renovation of protected buildings is not sufficiently developed. The traditionally used engineering methods are based on various simplifications regarding the modelling of the research question. As a consequence, the typically applied modelling techniques are often not able to depict the hygro-thermal behavior of the building elements in enough detail that freedom of damage can be guaranteed. The result of this uncertainty is the rejection of measures increasing energy-efficiency because of fear of building damage. Research work and the implementation of best-practice examples can help mitigate this issue.

\section{The individual diversity complicates standardization}

The diversity of geometrically and material-caused variations requires a careful inventory, individual planning as well as tailor-made structural and technical solutions. This is often cost-intensive and prone to error. The development of respective renovation techniques could demonstrate a high level replicability, not only for protected buildings, but also for the whole renovation market. 


\section{Conflicting administrative decisions of different public authorities}

Due to varying legislative requirements across different jurisdictions, a number of different public authorities may have to approve the refurbishment activities within a protected, historic building: in general the building authority (of the city or the region) has to approve the refurbishment with respect to the local building law. In addition to this, a national heritage agency (or a similar institution) may be responsible for ensuring compliance with national or special laws for the protection of historical buildings. If this dual legal requirement exists, both public authorities may issue their own administrative decisions which may be in conflict with the decision of the other public authority (with regard to the relevant laws in each jurisdiction). Furthermore, if the historic building is a part of a protected ensemble of historic buildings further public committees may be involved in the approval process: in general these committees typically have a consultative function only, and whilst the recommendations of their experts' reports are often not mandatory for the public authorities they have a strong influence on the decision making process. Where such conflict arises in the approval process of refurbishment for significant protected buildings, the building approval process becomes highly complicated. The resulting «Gordian Knot» may often only be solved by a redesign of the refurbishment project and an intensive communication strategy. As such the timeframe for obtaining building approvals from each jurisdiction can often be difficult to forecast in these circumstances, leading to high degree of uncertainty in the project schedule.

\section{Different approaches of the various interest groups}

In the discussion regarding monument protection and climate change, scientists and engineers meet art historians and architects, who all represent their own views. The different approaches of the people involved often make mutual understanding difficult. The differences mainly manifest themselves in two ways: on the one hand, the culturally-artistically shaped people tend to debate on a qualitative level, while scientists tend to stick to numerical data. On the other hand, passionate representatives of monument protection often argue based on individual cases which also require individual approaches. The scientific-technical way, however, requires the search for the commonalities among all individual cases, in order to find hidden principles, from which generally applicable rules can be derived.

\section{Difficult definition of funding for protected buildings}

The financial incentives in terms of funding for the thermal renovation of buildings are usually bound to achieving a certain - verifiable - energy demand. This demand either refers to the specification of an absolute value or it can be a pre-defined saving (in percentage) which has to be achieved. Due to the limitations caused by monument protection, those targets can often not be achieved and funding incentives remain ineffective. At the same time, it has to be considered that combined with requirements for monument protection, significant energy savings can be achieved through renovation or modernization. Even if the improvement is not enough to receive funding, a high amount of energy could be saved due to the energy-intensive performance before the renovation. An intensification of the already existing approaches to fund other smaller energy saving initiatives would result in the exploitation of additional renovation potential.

\section{The wish for timely integration}

Representatives of the Austrian National Heritage Agency (BDA) declare that they are often contacted at a very late stage of the project. A «timely» integration would offer the opportunity to commonly find a solution which is in line with the legislation. If the development process has progressed too far and important decisions have already taken place, it may happen that a negative administrative decision has to be issued. In that case, the opportunity to achieve a reduction of negative environmental impacts has not been taken advantage of. 


\section{Assistance during the approval procedure}

From a monument protection point of view, each building is unique and therefore also each building measure has to be approved separately. This has a massive influence on the process of renovation planning. When renovation measures are planned, often the question arises whether a special measure has to be approved or not. The individuality of the permit prevents the introduction of respective guidelines. The standardization of evaluation processes as in the sciences is therefore not possible in the field of monument preservation. In order to reduce those uncertainties, the Austrian National Heritage Agency (BDA) has developed guidelines called «Energy efficiency at Historical Buildings» [12]. In the course of this extensive document, the planners find advice regarding whether certain renovation measures need approval. Fig. 15 shows a selection of different guides, which aim at supporting planners of protected buildings.

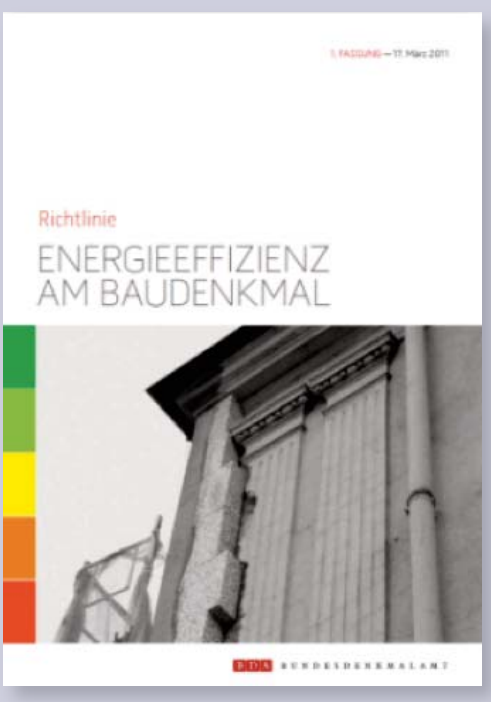

\section{Leitfaden zur energetischen Sanierung}

für die Westliche Innenstadt in Fürth

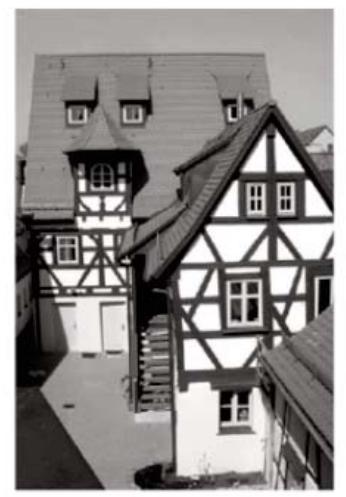

Kurzinformation für Eigentümer denkmalgeschützter Hẫuset
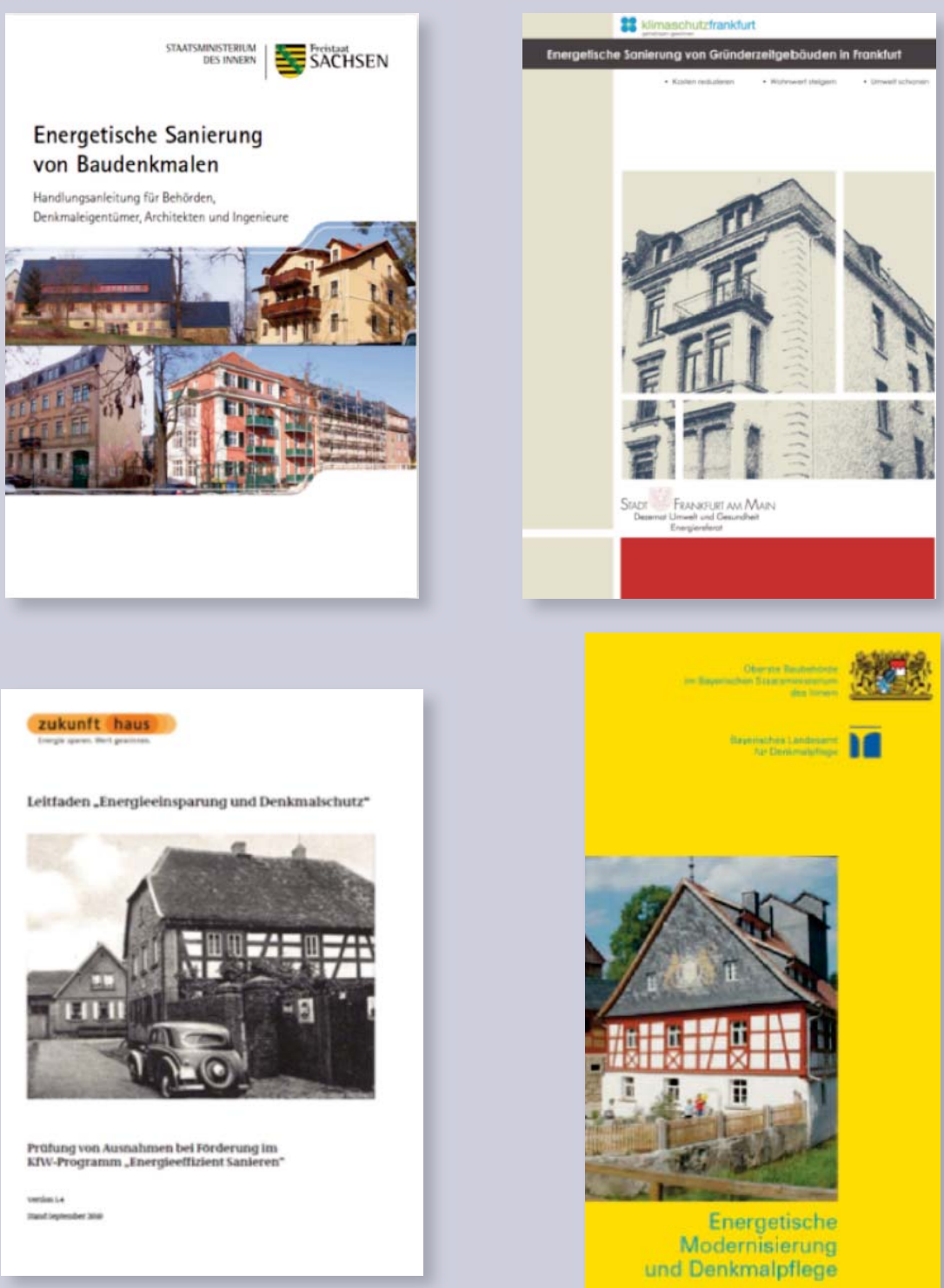

Figure 15(a): Guidelines supporting planning measures for protected buildings. Upper row from left to right: [12], [13], [14], second row from left to right [15], [16], [17]. 
冓

Building Regulations and

Historic Buildings:

balancing the needs for energy conservation with those of building conservation

An Interim Guidance Note on the application of Part L

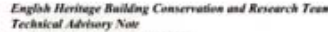

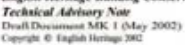
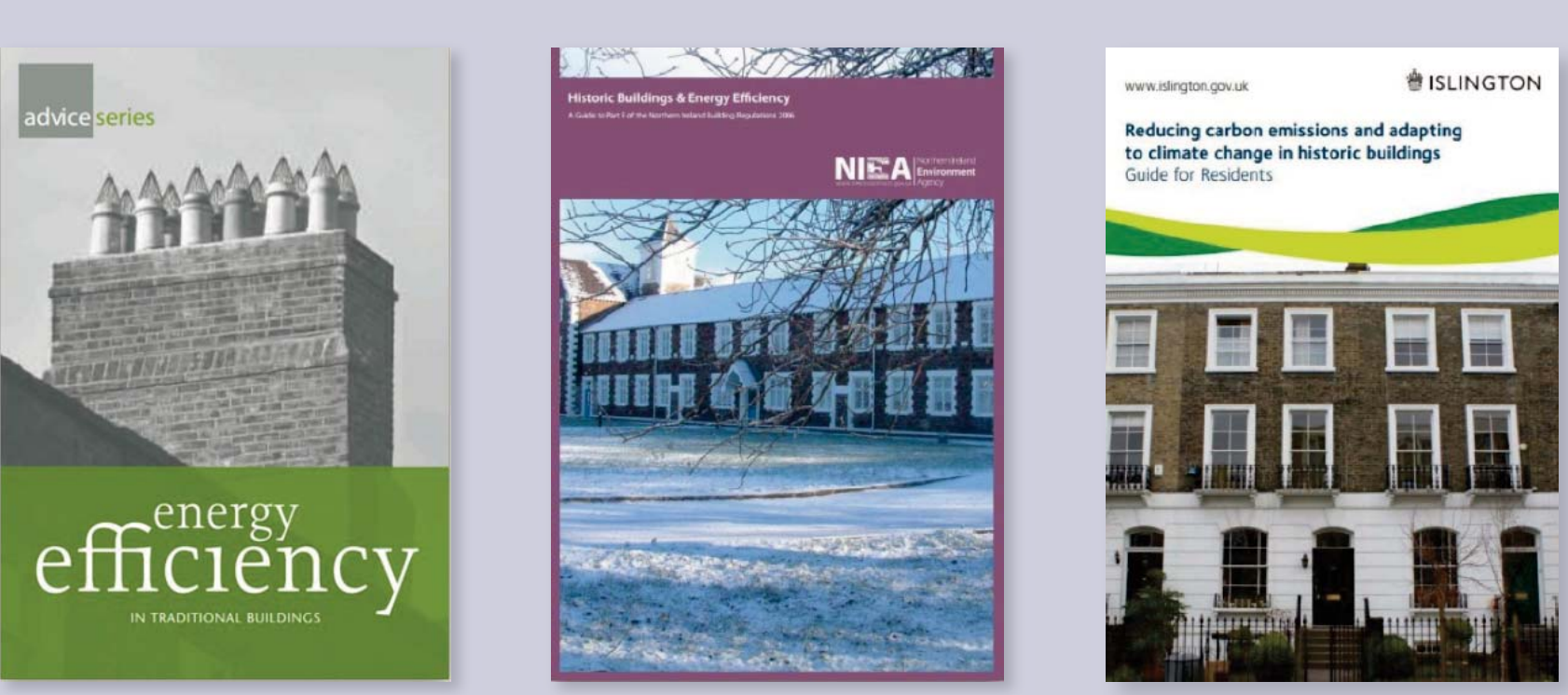

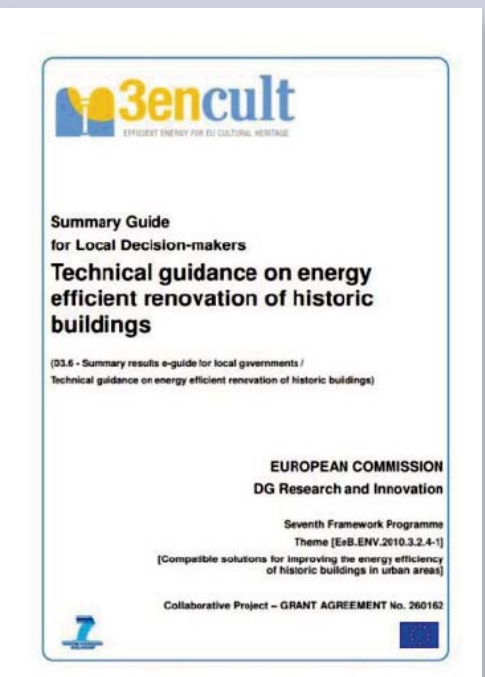

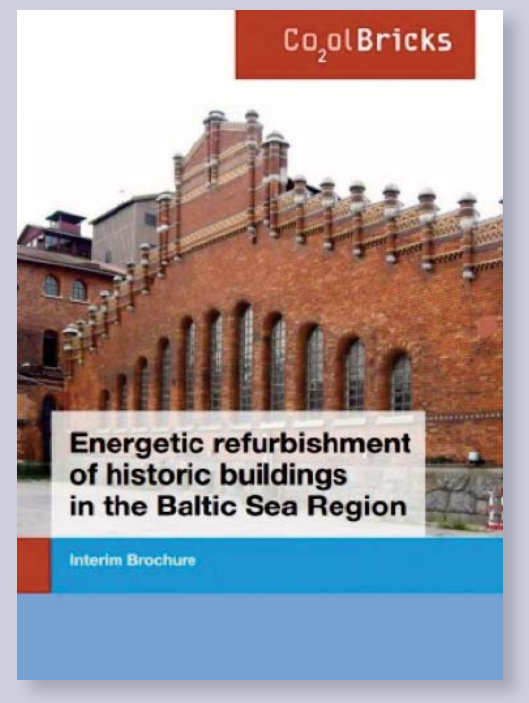

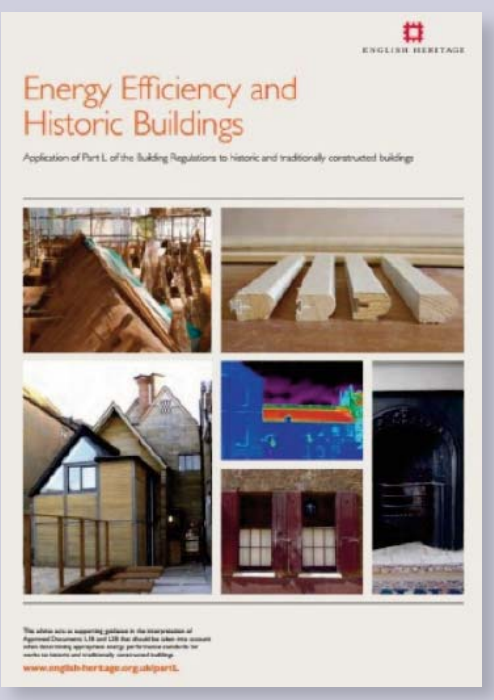

Figure 15(b): Guidelines supporting planning measures for protected buildings. Upper row from left to right: [18], [19], [20], second row form left to right: [21], [22], [23], last row [24], 


\subsection{Need for action}

It has been shown that the area of tension between monument protection and climate change has not been sufficiently discussed so far. A constructive debate about acceptable renovation solutions for culturallyhistorical buildings has hardly taken place so far. The missing knowledge inhibits the search for renovation measures which are compatible with monument protection. The discourse between the two interest groups of monument protection and climate change has to be intensified in order to increase mutual understanding to use this as a basis to commonly look for approaches for relevant renovation methods.

If respective renovation solutions cannot be found, protected buildings will become less attractive for owners and tenants. This may have the effect that protected buildings remain unused, meaning that financial means to maintain the building are absent, causing (in the long term) a decay of the building in question. To avoid such a scenario is in the core interest of both monument and climate protection to develop appropriate renovation methodologies that meet the needs of users, comply with updated regulations where possible and retain the historical significance and structure of buildings.

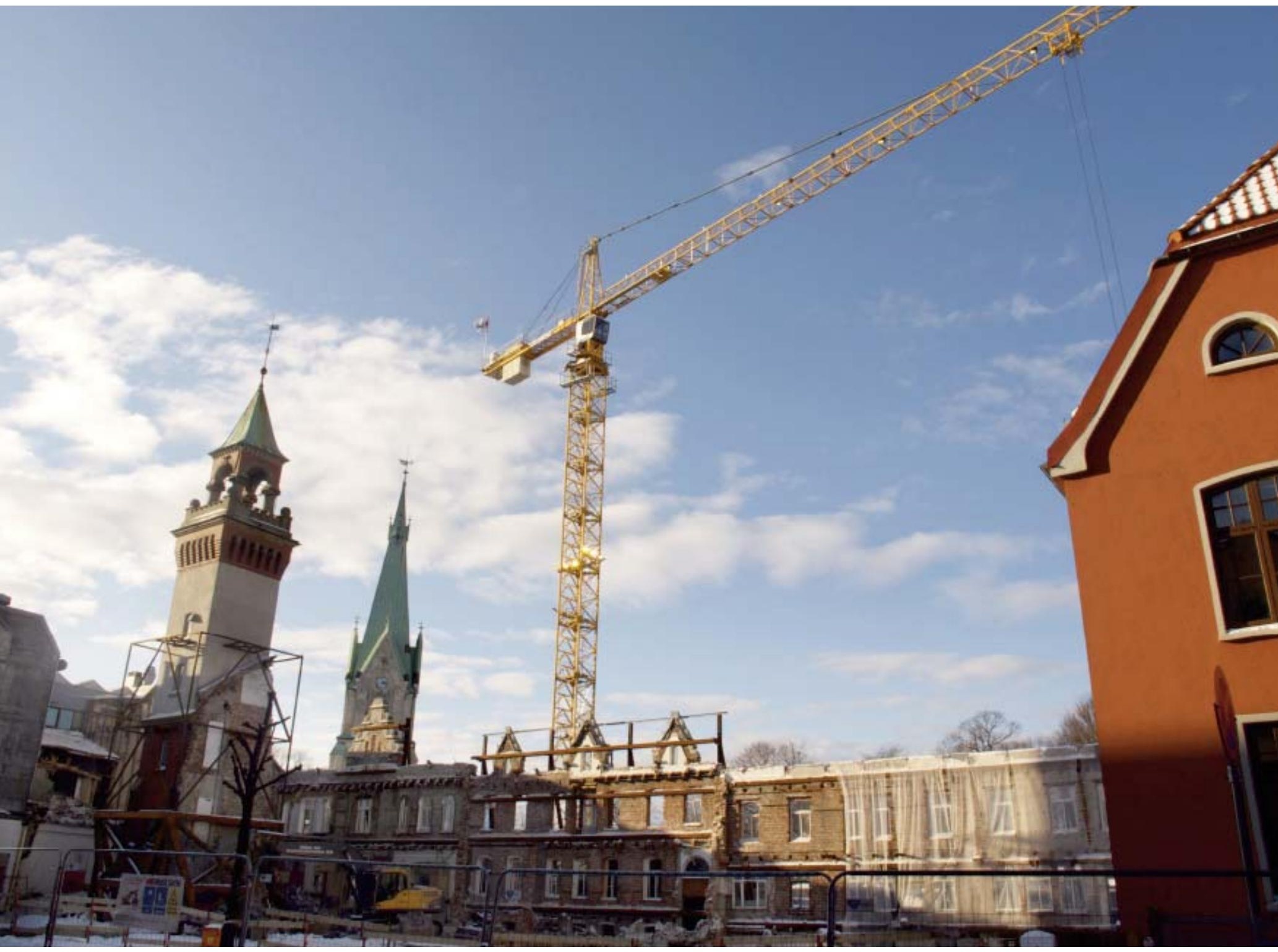




\section{EXAMPLES OF EXISTING DECISION MAKING SUPPORT TOOLS}

The study of decision making processes in chapter three shows that the chosen upgrading strategies and ambition levels are based on a mixture of objective facts and non-rational elements. In order to increase the quality of the decision making, it is important to structure the relevant information into a system which gives the right type of information at the right stage in the decision making process.

The Task has studied some existing tools which support good decision making processes for the upgrading of existing buildings. The examples described in the sections are good tools to facilitate a better decision making process.

\subsection{ECBS Annex 36}

The main objectives of the research project IEA ECBCS Annex 36 - Retrofitting of Educational Buildings [26] were:

- To provide tools and guidelines for decision makers and designers to improve the learning and teaching environment of educational facilities through energy- efficient retrofitting.

- To support decision makers in evaluating the efficiency and acceptance of available concepts.

- To give recommendations on how to operate the retrofitted buildings.

- To promote energy- and cost-efficient retrofit measures.

One of the results was the "Energy Concept Advisor» which is a web-based software tool to assist decision makers in retrofitting processes. The gateway to the tool gives such options for the user:

\section{ENERGY CONCEPT ADVISER}

\section{for Technical Retrofit Measures}

\begin{tabular}{r|r}
\hline obtain recommendations for specific problems in your building & Recommendations \\
\hline study more than 30 retrofitted buildings and retrofit measures & $\begin{array}{r}\text { Case Stu dies } \\
\text { Retrofit Measures }\end{array}$ \\
\hline compare your building's consumption to national data & Performance Rating \\
\hline develop an energy efficient retrofit concept for your building & Retrofit concept \\
\hline programs and methods to analyse your building performance & Utilities \\
\hline
\end{tabular}




\subsection{SURE}

«SURE!» [27] is an inter-Nordic project focused on optimizing energy usage and strengthening sustainable lifestyles for residents in areas that need retrofitting - effectively and at a low cost. This is done through a technology for diagnosing and optimizing heating and indoor comfort in existing buildings, supplemented by user interfaces designed to achieve sustainable, energy-efficient habits.

The output will be a low-cost, effective and innovative retro-fitting concept that combines patented technology, open ICT platforms and interaction design validated through real life demonstrations."

From the project web-page:

The result of the project is a "SURE Guideline» which can be found at this web-address:

http://sustainablerefurbishment.wordpress.com/the-sure-guideline/

\subsection{UPGRADE Solutions}

In the norwegian national research project, connected to IEA SHC Task 47 project, the SURE Guideline has been developed further to a national guideline in Norwegian, found on the webpage:

www.upgradebuildings.no

\subsection{0ther examples}

In the paper «Defining and Developing an Energy Pre-Retrofitting Approach» by Luther and Rajagopalan [28], the authors studied different tools for assessing buildings to be retrofitted. Most of these focus on one particular item and neglecting others. One exception is the systematic incorporation of Building Energy Management System (BEMS) data such as loads, demands and user requirements, Doukas et al, 2009 [29].

Luther and Rajagopalan conclude that there is a missing stage which they call the «integrity audit». This audit identifies waste, missed opportunities and rescheduling of the operation of equipment. This is done in four stages:

1. Development of a building performance retrofitting management plan and its commitment.

2. A «Building Integrity Audit» comprising a comprehensive overview of building services, energy systems and building fabric, mechanical and occupant loads scheduling, control, and identifying energy waste.

3. Pre-retrofitting Energy Management understanding the scheduling, control and energy use through sub-metering

4. Implementing a staged and ranked approach to retrofitting the building services, systems and fabric. 


\section{RECOMMENDATIONS}

\subsection{Introduction}

In IEA SHC Task 47 mainly offices and school buildings have been studied. We have no examples of wholesale and retail buildings which, as discussed in chapter 2, represent one of the largest energy saving potentials. New research projects should have a closer look at this very important segment.

On an international level the report «EUROPE'S BUILDINGS UNDER THE MICROSCOPE» by BPIE [8] discusses the potential, challenges and recommendations for the whole building stock in Europe. The final recommendations are structured in a way to counter the four main categories of barriers:

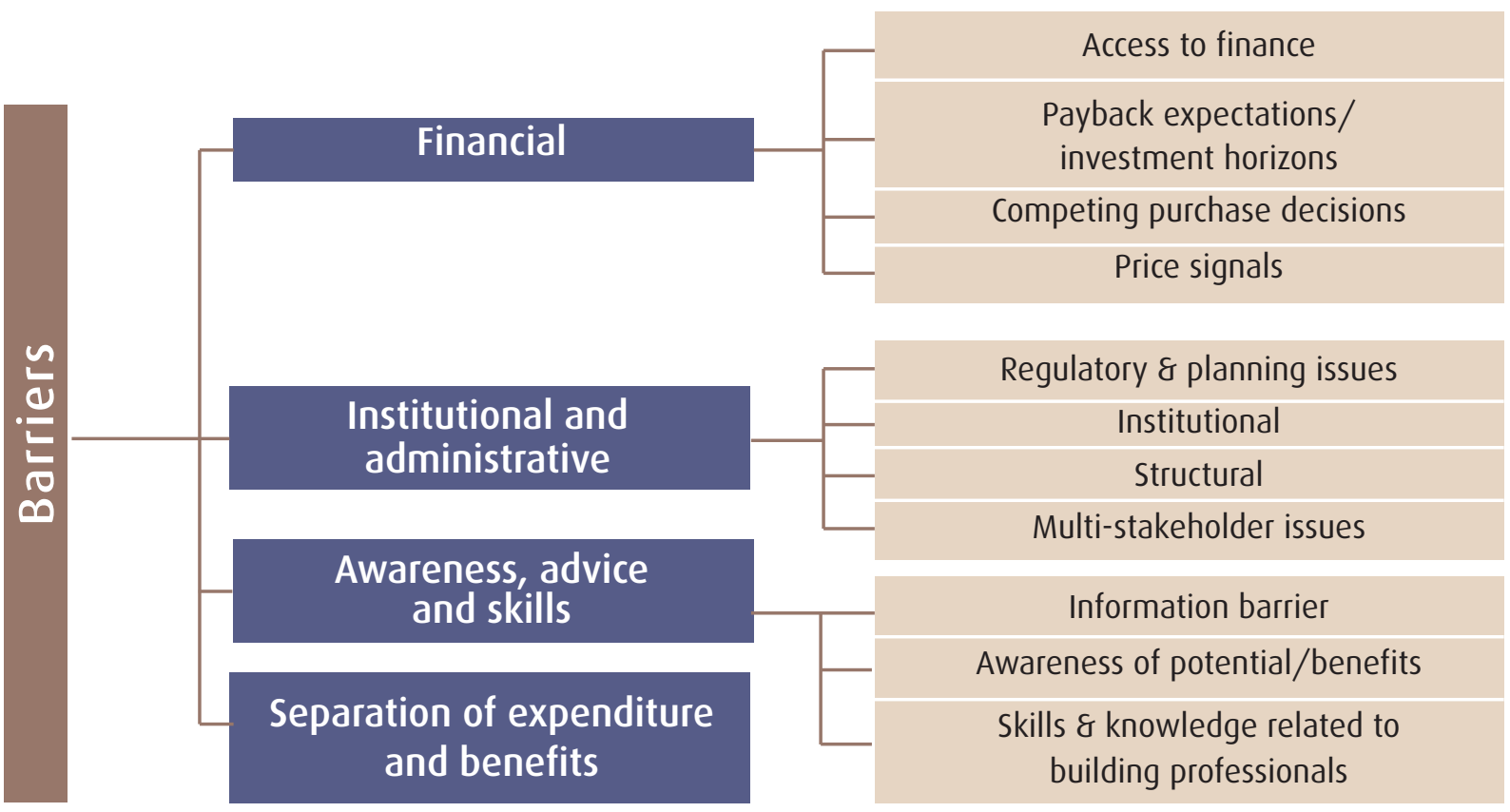

The recommendations include proposals of how the European Union and the national states may act to increase the number and ambition level of upgrading projects of existing building stock. Relevant policy measures are required to strengthen legislation and further develop the energy labeling system. Use of financing measures both on an EU and national level should be offered to upgrading projects meeting defined criteria. Further, training and education measures are important to improve the knowledge level and practice in renovation activities. More of the specific recommendations may be read in the report, which is available through this link; http://bpie.eu/eu_buildings_under_microscope.htmI\#.VDMWItKKDbg

As the main findings from the research within IEA SHC Task 47 are from ten specific upgrading projects, our approach is from a «micro-perspective», while BPIE's report is from a "macro-perspective». Therefore there are complementary findings but also confirmation of some of the other recommendations.

In the next two sections we have summarized recommendations to authorities and to the industry respectively. The suggestions are structured in accordance with Lawrence Brown's [30] four broad perspectives: 
- The communication perspective: the idea behind this perspective is that innovation diffusion is primarily driven by communication within a society

- The development perspective: this perspective explains diffusion by improvements made to the innovation itself over time

- The economic history perspective: this perspective is highly concerned with affordability and starts from the assumption that potentential adopters in a society have unequal access to resources like money and/or credit

- The market infrastructure perspective: this perspective pays greater attention to the availability at or near the location of the potential adopter: without availability the person or household will not have the option to adopt in the first place

To simplify the essence of each perspective, the questions for ambitious upgrading projects could be rephrased:

- Is the innovation attractive?

- Is the innovation competitive?

- Is it affordable?

- Is it available?

Note that before an innovation may be recognised as attractive, the awareness must be in place.

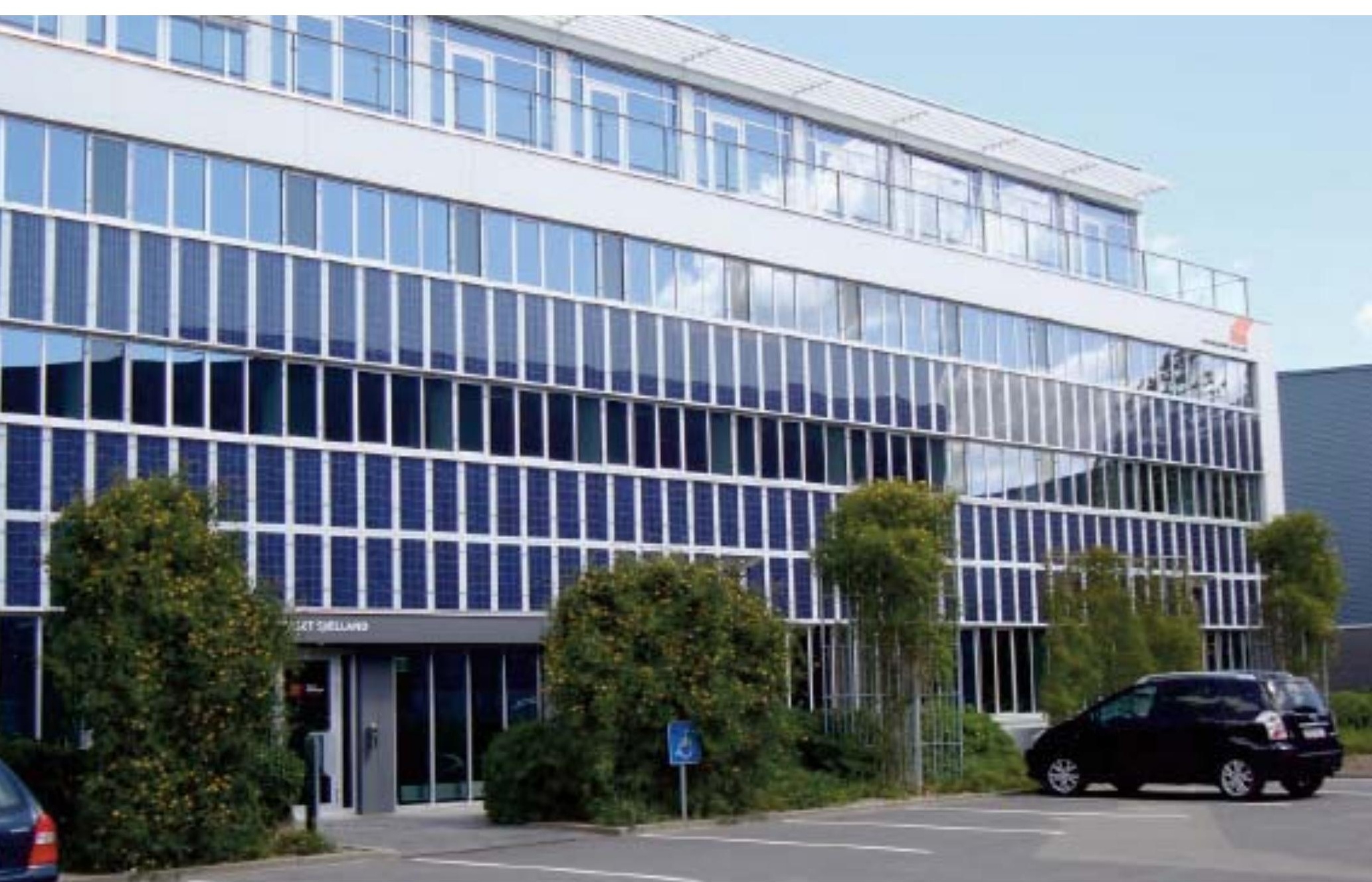




\subsection{Recommendations to authorities}

By systematically studying the drivers and barriers discussed in chapters 3.5 and 3.6, suggestions for how to strengthen the drivers and how to eliminate or reduce the barriers have been developed. In table 11 the recommendations to authorities are presented:

\section{AUTHORITIES}

Increase attractiveness affordable

\section{Increase competitiveness}

\section{Strengthen drivers}

- As part of information campaigns use relevant media and conferences to show good examples.

- Place particular spotlight on the enthusiasts (both within owner organization and advisors).

- Actors receiving grants also see this as confirmation of a good decision and see this strengthening the organization's image.

\section{Eliminate barriers}

- Develop convincing arguments for nZEB.

- Endorse serious frontrunners.

- In some countries it is obligatory that companies have a statement about their impact on the environment. This could be extended by an obligation to state what energy labels their buildings hold. This increases the awareness of the issue of the energy efficiency of buildings.

- Increased tax on energy.

- Energy labelling systems provide a neutral reference for comparing buildings on energy per formance and thereby increase the focus on this as a competitive advantage.

- Stronger subventions programs for owners upgrading towards nZEB (driver in some projects).

Make it more available
- Make sure the top management of building owner companies see the benefits of nZEB upgrading and as a consequence they will be more open for such initiatives within their own projects.
- Put in place training programs for all relevant crafts to be updated on nZEB upgrading.

- Announce stepwise enforcement of building codes.

- Stronger subventions programs for owners upgrading towards nZEB standard (barrier in other projects).

- When public bodies upgrade their own buildings, nZEB ambition should be required. In this way both experience and good examples are developed locally. Tender processes must be defined adequately to avoid pure focus on price. A partnering contact for the design phase seems to be a good solution for this.

- Facilitate arenas for the industry to meet with researchers and other companies to share experiences.

Table 11: How authorities can contribute to increase the number of nZEB retrofitting projects.

\section{How to increase attractiveness of nZEB upgrading of non-residential buildings?}

Authorities should support the existing drivers such as the general public interest in media and enthusiastic innovators who want to talk about their success stories. This should be done by coordinated information campaigns and by continuing to develop adequate subsidy schemes, which support ambitious projects both financially and through recognition for the involved stakeholders. Good information campaigns also serve to combat some of the major barriers to innovative projects by addressing strong arguments for nzEB upgrading and by endorsing the contributors to the innovative projects.

Another important barrier that can be addressed by good information campaigns is promoting discussion among both public and private building owners regarding the possibilities for going beyond existing building codes when a specific building needs major upgrading. All too often a lack of consciousness around these opportunities means that potential high ambition projects do not consider energy efficient technologies and process in the initiation or needs definition phases. In the case studies we have seen examples that this even happens in organizations that have defined "green strategies». In order to increase the focus, it could be a requirement that all organizations have to state information about the energy efficiency rating of their buildings in the annual report. For example, in Australia, all office buildings 
with a floor area of more than 2,000m2 must disclose their energy performance publicly using a NABERS star rating when selling or leasing the building. This measure is intended to make energy performance a market driver for building upgrades that achieve greenhouse gas emission reductions in their operation.

\section{How to increase competitiveness of nZEB Renovations?}

The most obvious measure to increase the competiveness of nZEB renovation is to make energy wastage more expensive through increased taxation on energy consumption. Energy labelling systems which have been introduced in many countries will make it possible to compare the energy efficiency of different buildings. The implementation of such systems have to be supported by the information campaigns mentioned above in order to increase the consciousness among tenants about the consequences of choosing a building with poor efficiency rating.

As nZEB upgrading is still at an early phase in its development, the availability of competence in planning and construction of such projects is scarce. It is the responsibility of the authorities to put in place training programs for all those involved in an upgrading project, including designers, contractors, facility managers and maintenance providers.

National authorities should communicate the pathway for planned enforced building code changes in order to make clear that all stakeholders have to prepare for continuous improvements to the energy efficiency of buildings.

\section{How to make nZEB Renovations more affordable?}

In the case studies we have seen that subsidies and grants have been a driver for several projects whilst the lack of such financial means have been a barrier for others. It is difficult to conclude how strong such financial measures have to be in order to make a difference. This varies considerably between the projects studied. For some projects, such as the Italian school, the high share of subsidies was crucial in realizing the ambitious project. While for the Danish kindergarten no subsidies were needed.

\section{How to make nZEB Renovations more available?}

The most important means by which authorities at all levels can increase the uptake of nZEB renovations is to be a frontrunner and requesting such standards for their own upgrading projects. This will start a demand driven development of the market that makes it more interesting for more suppliers. The competence that gradually develops on the supplier side will be of benefit to private building owners as well.

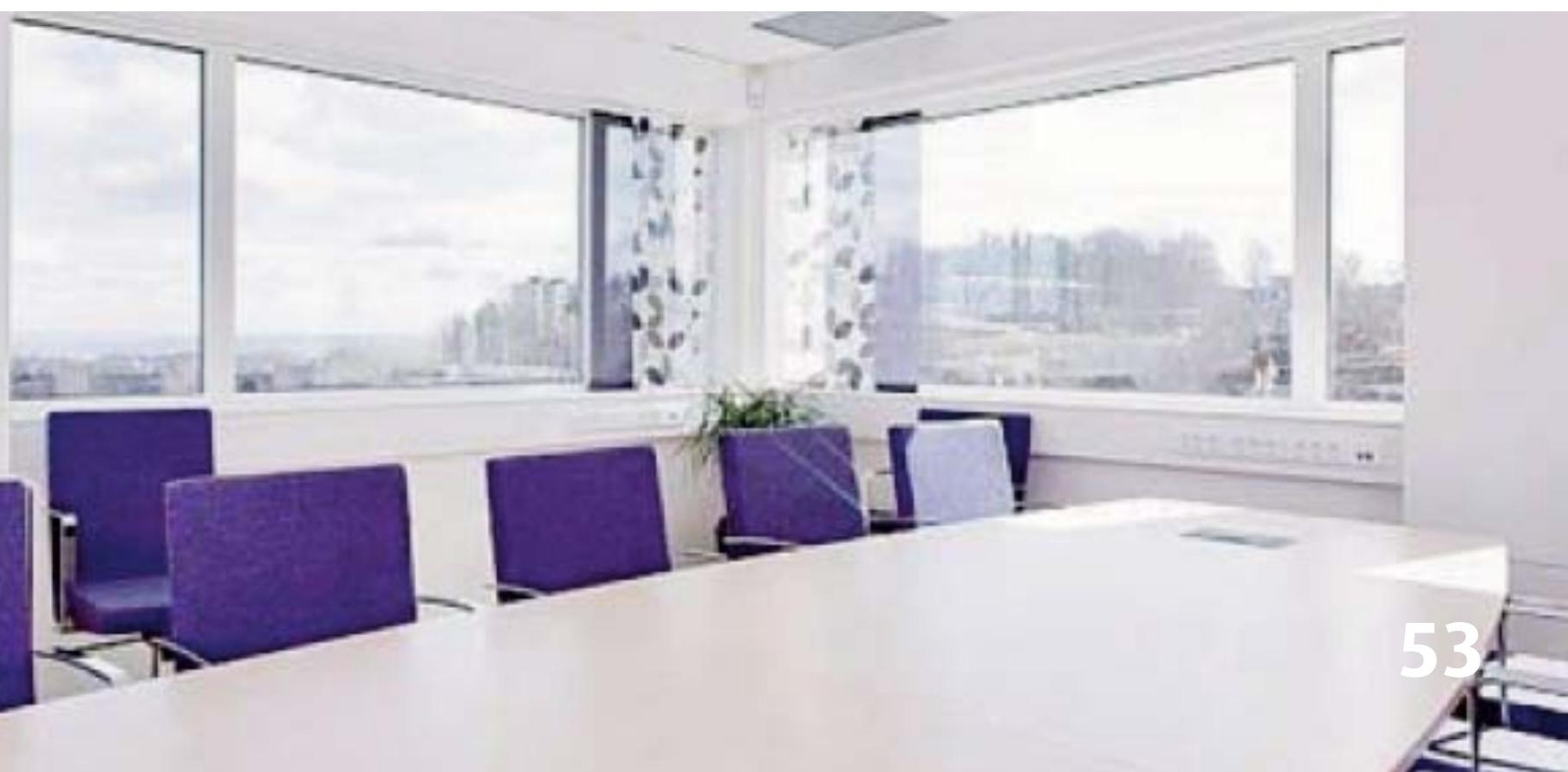




\subsection{Recommendations to the construction industry}

The recomendations to the construction industry are presented in table 12 in the same structure as above:

\section{INDUSTRY}

Increase attractiveness

Increase competitiveness

\section{Make it more} affordable

\section{Make it more available}

\section{Strengthen drivers}

- Identify the owner segments which focus on sustainability.

- Use relevant media and conferences to show good examples.

- Place spotlight on the enthusiasts (both within owner organization and advisors).

- Research projects which focus on combining best innovations on component level in order to make more efficient retrofitting processes.

- Smart changes of floor plan can improve the area efficiency per employee. Also smart extensions of the existing building, for instance add an extra floor on the top may also improve the economy of the project.

- Offer of ESCO contracts where the owner pays in accordance with the energy savings obtained.

- Spread the experiences to new regions so new potential clients can see good examples in their neighbourhood.

- Make sure the top management of building owner companies see the benefits of nZEB upgrading and as a consequence they will be more open to such initiatives within their own projects.

\section{Eliminate barriers}

- Develop convincing arguments for nZEB.

- Better initial audits of the building will reduce the amount of unforeseen challenges.

- Systematic training programs to update the skills of all personnel involved in the projects; from planning, construction and hand over/use.

- Use of QA tools to assure the quality of a) products/systems, b) competence of the involved actors and c) processes.

- Offer of financing as part of the upgrading package.

- As it is a challenge to do deep retrofitting while the tenants stay in the building, use of prefa bricated solutions may reduce the level of dis turbance as well as the length of the on site retrofitting process.

Table 12: How the construction industry can contribute to increase the number of nZEB retrofitting projects.

The points in red text illustrate that they are common with the recommendations to the authorities, meaning that here joint efforts should be undertaken. But also other points work in conjunction with the measures needed to be taken by the authorities.

\section{How to increase attractiveness of nZEB upgrading of non-residential buildings?}

The Construction Industry has to work with authorities to increase the awareness and subsequently the attractiveness of nZEB upgrading by developing convincing arguments that support the business case for high ambition projects. This must include the non-energy benefits (NEB), such as better indoor environment quality (cleaner air, steady temperature, etc), increased value of the building (as it competes with new buildings as shown in the case of Solbråveien) and improved image by showing that the organization takes on a responsibility for reducing its carbon footprint.

For the individual companies with ambitions to be among the market leaders it is important to identify the owner segments which have special attention to sustainability.

\section{How to increase competitiveness of nZEB Renovations?}

The Construction Industry in general, and the leading companies in particular, must address their research into combining smart energy efficiency solutions and efficient installation processes. This also includes the 
use of prefabricated solutions that aim to shorten the on-site construction period, which is often of particular importance in retrofitting projects. In the Norwegian Tax Administration building, for example, such prefabricated solutions included the façade elements, which eliminated the need of a costly «tent» to secure the huge building and ensure that it remained dry throughout the whole construction period. In several of the projects, the cost efficiency per employee has been improved by smarter layouts of the building and in some cases combined with an extension of the existing building.

We have seen that the planning in the initial phase was not good in some of the projects and this caused challenges later in the process, which otherwise could have been avoided. It is therefore crucial to make use of good initial audits of the building at an early stage. This combined with good quality assurance and benchmarking tools and standards, for example BREEAM, is strongly recommended. Companies must also recognise the need for systematic training programs of all personnel involved in the projects.

\section{How to make nZEB Renovations more affordable?}

In many countries there are already in place so called ESCO companies (Energy Saving Companies) which offer models where the owner pays for the investment as a function of the energy savings. For some projects this may be a relevant proposition for customers with limited financial resources or as a mean to reduce the risk of the investment for the owner.

\section{How to make nZEB Renovations more available?}

The best motivation for a building owner to pursue a nZEB upgrading of a building is if there is local, relevant examples completed by local contractors. When this is the case, nZEB is can often be easily achieved. It is therefore important that the experiences are spread throughout each country as rings in the water radiating out from a central disruption. It is also important to make sure that the message of the advantages of nZEB renovation reaches the top management of large organizations, as we have seen the importance of the involvement of top leaders in many of the projects.

The availability of a complex upgrading process also depends on whether the tenant has to stay in the building during the renovation or not. By using more prefabricated solutions both the on-site construction period as well as the environmental impacts of construction, such as noise, dust and pollution may be reduced, and thereby make it more possible to upgrade the building whilst still occupied by the tenant.
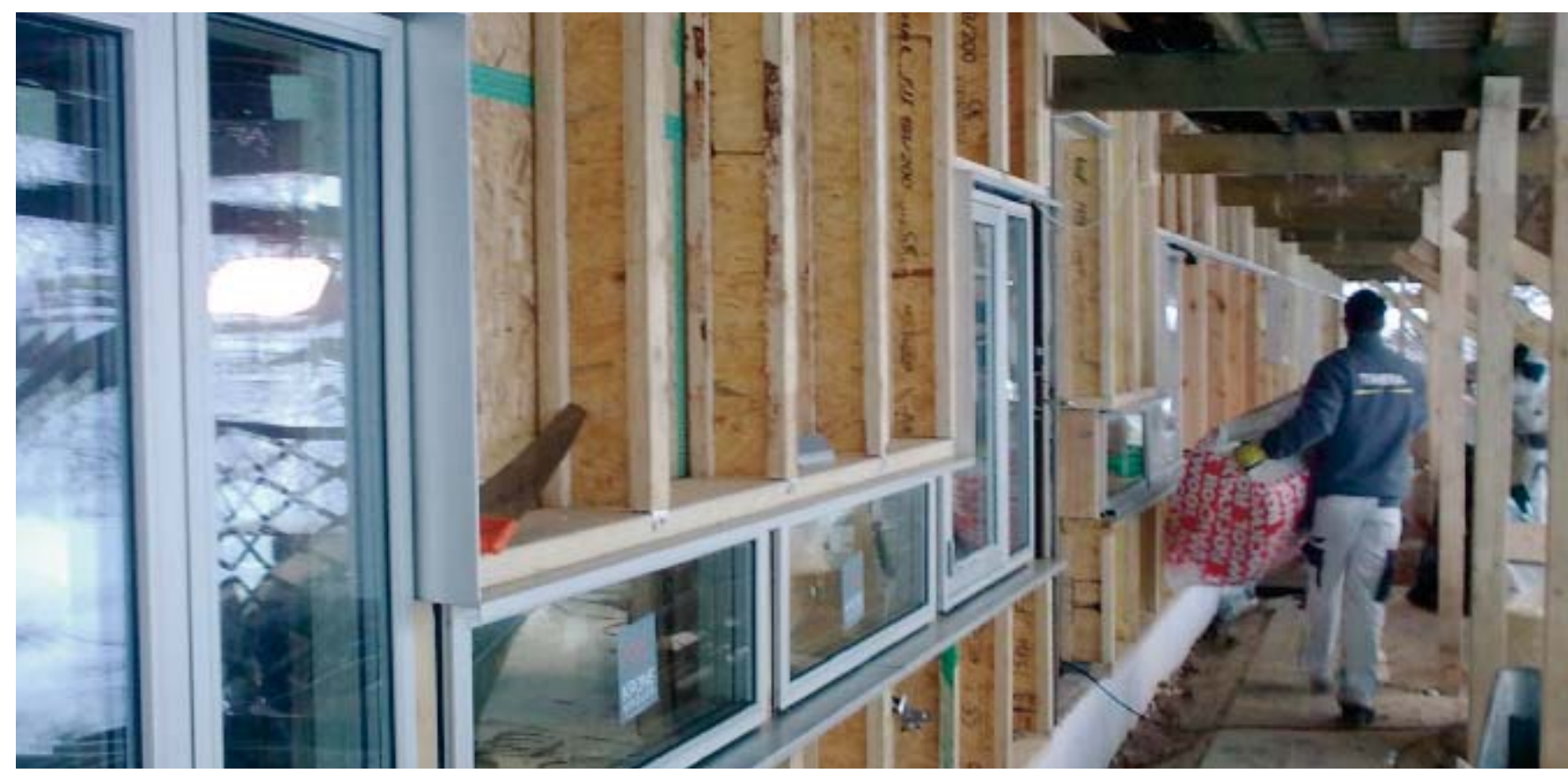

Kindergarten in Høje-Taastrup, Denmark. Photo: Høje-Taastrup municipiality 


\subsection{Final remark}

The final decision regarding ambition level of project will always be taken by the owner of the building. As we are still in the introduction phase of the nZEB market development, Carlson \& Wilmot's «The Five Disciplines For Creating What Customers Want», presented in chapter 3.1, are very relevant to the owner in achieving an innovative nZEB upgrade for their building. These five principles include to:

- Make sure there is a holistic understanding of the tenant's needs - which normally encompasses more than just energy efficiency.

- Develop solutions offering values which completely fulfill the needs.

- Make sure there are one or more enthusiastic persons who are committed to the process.

- Organize a multi-disciplinary team (also involving occupants).

- Make sure that the project is supported by the top management and is in line with the company strategy. 


\section{References}

1. International Energy Agency, 2014, link: ww.iea.org/aboutus/faqs/energyefficiency/

2. Overview of Member States information on NZEBs, Working version of the progress report - final report, Ecofys, October 2014. Link:

http://ec.europa.eu/energy/efficiency/buildings/doc/2014_nzeb_progress_report.pdf

3. «Baseline Energy Consumption and Greenhouse Emissions in Commercial Buildings in Australia» (2012), the Department of Climate Change and Energy Efficiency, link http://www.industry.gov.au/Energy/EnergyEfficiency/NonresidentialBuildings/Documents/CBBSPart-1.pdf.

4. Varmebesparelse ved løbende bygningsrenovering frem til 2050, SBi, 2014, www.sbi.dk

5. Statistics Denmark, http://dst.dk/en

6. Potensial- og barrierestudie, Energieffektivisering i norske yrkesbygg, Enova, 2011

7. Article 4 Building Renovation Strategies to the European Commission, EED art. 4 Paragraph 3.2.2 in the Italian NEEAP, 2014. Link:

http://ec.europa.eu/energy/efficiency/eed/article4_building_strategies_en.htm

8. Europe BPIE's "Europe's Buildings under the Microscope, BPIE, October 2011, http://www.bpie.eu/uploads/lib/document/attachment/20/HR_EU_B_under_microscope_ study.pdf

9. Diffusion of Innovations, fifth edition, Rogers, E., Freepress, 2003

10. Innovation: The Five Disciplines For Creating What Customers Want, Carlson, C.R., Wilmot, W.W., Crown Business, 2006

11. denkmalaktiv I, Refurbishment of old and listed buildings to active-house standards?, Austrian research project funded by the «Climate and Energy Fund», 2009 - 2013

12. BDA (Austrian National Heritage Agency), Guideline «Energy Efficiency at Historical Buildings» (in German), 1st edition, Vienna, 17th of March 2011

13. «Energetic Refurbishment of Historical Buildings» (in German), Saxon Federal Ministry of the Interior, Dresden, 2011

14. «Energetic Refurbishment of Historical Buildings of the late 19th to early 20th Century in Frankfurt» (in German),2nd edition, Frankfurt am Main, 2009

15. «Guideline for the Energetic Refurbishment of the Western Part of the Innercity of Fürth» (in German), brief information for owners of protected buildings, Building Authority of the City of Fürth, 2007

16. Guideline «Energy Conservation and Monument Protection» (in German), German Energy Agency (edition 1.4), Berlin in September 2010

17. «Energetic Refurbishment and Preservation of Monuments» (in German), Supreme Building Authority of the Bavarian State Ministry of the Interior and Bavarian Authorities for Monument Protection, Munich, 2009

18. «Building Regulations and Historic Buildings»: (in English) balancing the needs for energy conservation with those of building conservation. An Interim Guidance Note on the application of Part, L. English Heritage, 2004.

19. «Energetic refurbishment of historic buildings in the Baltic Sea Region»: (in English) Cozol Bricks Climate Change, Cultural heritage and Energy Efficient Monuments, Brochure 04 - Interim Brochure. Free and Hanseatic City of Hamburg, Department of Heritage Preservation, Hamburg in September 2012

20. «Energy Efficiency and Historic Buildings»: (in English) Application of Part L of the Building Regulations to historic and traditionally constructed buildings. Published in March 2011 by English Heritage.

21. «Energy Efficiency in Traditional Buildings»: (in English) (DoEHLG Advice Series) Department of the Environment, Heritage and Local Government, 2010. 
22. "Historic Buildings \& Energy Efficiency»: (in English) A Guide to Part F of the Northern Ireland Building Regulations 2006, Northern Ireland Environment Agency, 2006

23. "Reducing carbon emissions and adapting to climate change in historic buildings»: (in English) Sustainable Historic Buildings - Guide for Residents, Islington

24. «Technical guidance on energy efficient renovation of historic buildings»: (in English) Summary Guide for Local Decision-makers, European Commission DG Research and Innovation, Seventh Framework Programme - Compatible solutions for improving the energy efficiency of historic buildings in urban areas, Bolzano/Italy march 2013

25. Other relevant links related to renovation of historic buildings:

http://www.riksantikvaren.no/filestore/Energieffektiviseringaveksisterendebygningsmasse.pdf http://ohp.parks.ca.gov/pages/1054/files/english\%20heritage\%20interim_guidance.pdf http://www.riai.ie/uploads/files/Conservation_Guidelines_December_2010.pdf

26. IEA ECBCS Annex 36 - Retrofitting of Educational Buildings; link: http://www.onnex36.com/

27. SURE, wWw.sure-project.net

28. Defining and Developing an Energy Pre-Retrofitting Approach, Luther, M.B. and Rajagopalan, P, Journal of Green Building, 2014

29. Assessing energy-saving measures in buildings through an intelligent decision support model, Building and Environment 44 290- 298, Doukas, H, Nychtis, C and Psarras, J, 2009

30. Innovation Diffusion, Brown, L., Methuen, New York, 1981 


\section{ANNEXES}

\section{Contents of separete annex document:}

Annex 1: $\quad$ Danish Non-Residential Building Stock ................................................. 3

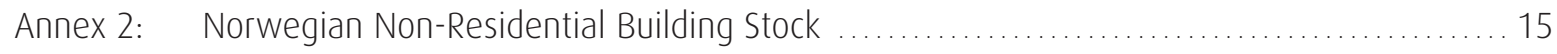

Annex 3: $\quad$ Italian Non-Residential Building Stock ................................................ 24

Annex 4: $\quad$ Questionnaire Decision-Making Processes .......................................... 29

Annex 5: $\quad$ Office Building, Sydney, Australia - Decision-Making Process _........................... 36

Annex 6: $\quad$ Science-Montoyer in Brussels, Belgium - Decision-Making Process ....................... 46

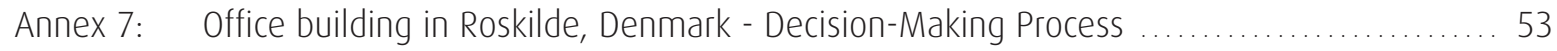

Annex 8: $\quad$ Office Building in Asker, Norway - Decision-Making Process ............................. 59

Annex 9: $\quad$ Norwegian Tax Administration Building, Oslo, Norway - Decision-Making Process ......... 70

Annex 10: City Hall in Kristiansand, Norway - Decision-Making Process ............................ 83

Annex 11: Renovation of School in Cesena, Italy - Decision-Making Process . . . . . . . . . . . . ......... 96

Annex 12: School in Schwanenstadt, Austria - Decision-Making Process . .......................... 103

Annex 13: Kindergarten in Høje-Taastrup, Denmark - Decision-Making Process ..................... 110

Annex 14: Franciscan Monastery, Graz, Austria - Decision-Making Process ............................ 115 